\title{
Evaluating spatial and temporal variability in growth and mortality for recreational fisheries with limited catch data
}

\author{
Yan Li, Tyler Wagner, Yan Jiao, Robert Lorantas, and Cheryl A. Murphy
}

\begin{abstract}
Understanding the spatial and temporal variability in life-history traits among populations is essential for the management of recreational fisheries. However, valuable freshwater recreational fish species often suffer from a lack of catch information. In this study, we demonstrated the use of an approach to estimate the spatial and temporal variability in growth and mortality in the absence of catch data and apply the method to riverine smallmouth bass (Micropterus dolomieu) populations in Pennsylvania, USA. Our approach included a growth analysis and a length-based analysis that estimates mortality. Using a hierarchical Bayesian approach, we examined spatial variability in growth and mortality by assuming parameters vary spatially but remain constant over time and temporal variability by assuming parameters vary spatially and temporally. The estimated growth and mortality of smallmouth bass showed substantial variability over time and across rivers. We explored the relationships of the estimated growth and mortality with spring water temperature and spring flow. Growth rate was likely to be positively correlated with these two factors, while young mortality was likely to be positively correlated with spring flow. The spatially and temporally varying growth and mortality suggest that smallmouth bass populations across rivers may respond differently to management plans and disturbance such as environmental contamination and land-use change. The analytical approach can be extended to other freshwater recreational species that also lack of catch data. The approach could also be useful in developing population assessments with erroneous catch data or be used as a model sensitivity scenario to verify traditional models even when catch data are available.
\end{abstract}

Résumé : La compréhension de la variabilité spatiale et temporelle des caractères du cycle biologique entre populations est d'importance clé pour la gestion des pêches sportives. Un manque d'information sur les prises caractérise souvent les espèces de poissons d'eau douce visées par la pêche sportive. Nous démontrons l'utilité d'une approche pour estimer la variabilité spatiale et temporelle de la croissance et de la mortalité en l'absence de données sur les prises et appliquons cette méthode à des populations d'achigans à petite bouche (Micropterus dolomieu) vivant en rivière en Pennsylvanie (États-Unis). Notre approche comprend une analyse de la croissance et une analyse basée sur la longueur qui estime la mortalité. En utilisant une approche bayésienne hiérarchique, nous examinons la variabilité spatiale de la croissance et de la mortalité en postulant que les paramètres varient dans l'espace, mais pas dans le temps, et leur variabilité temporelle en postulant que les paramètres varient dans l'espace et le temps. La croissance et la mortalité estimées des achigans à petite bouche présentent une variabilité considérable dans le temps et entre rivières. Nous explorons les relations de la croissance et de la mortalité estimées avec la température printanière de l'eau et les débits printaniers. Le taux de croissance est probablement corrélé positivement à ces deux facteurs, alors que la mortalité des jeunes est probablement corrélée positivement aux débits printaniers. La variabilité dans l'espace et le temps de la croissance et de la mortalité donne à penser que les populations d'achigans à petite bouche de différentes rivières pourraient réagir différemment aux plans de gestion et à des perturbations comme la contamination du milieu et des changements d'utilisation du sol. L'approche d'analyse peut être élargie à d'autres espèces de pêche sportive d'eau douce caractérisées par un manque de données sur les prises. L'approche pourrait également être utile pour la préparation d'évaluations de population avec des données sur les prises erronées ou pourrait être utilisée comme scénario de sensibilité du modèle pour valider des modèles traditionnels même quand des données sur les prises sont disponibles. [Traduit par la Rédaction]

\section{Introduction}

Understanding the spatial and temporal variability in lifehistory traits among populations is essential not only to decipher the inherent within-species variability that may help guide management decisions, but also to identify potential environmental factors that can explain this variability (Myers et al. 2001; Helser and Lai 2004). In contrast with most commercially harvested species whose catches are reported by regulation after each fishing trip, however, many socioeconomically important recreational fisheries lack catch data, as management agencies may lack the resources to gather catch data for the many species that are managed as recreational fisheries. In addition, many recreational fisheries practice catch-and-release (fish are released unharmed), which complicates the collection of catch data. This lack of catch data is a limiting factor for conducting a comprehensive stock assessment for recreational fisheries because the commonly used stock

Received 6 February 2017. Accepted 15 November 2017.

Y. Li.* Pennsylvania Cooperative Fish and Wildlife Research Unit, Pennsylvania State University, University Park, PA 16802, USA.

T. Wagner. US Geological Survey, Pennsylvania Cooperative Fish and Wildlife Research Unit, Pennsylvania State University, University Park, PA 16802, USA.

Y. Jiao. Fish and Wildlife Conservation, Virginia Tech University, Blacksburg, VA 24061-0321, USA.

R. Lorantas. Pennsylvania Fish and Boat Commission, 595 E Rolling Ridge Dr., Bellefonte, PA 16823, USA.

C.A. Murphy. Department of Fisheries and Wildlife, Lyman Briggs College, Michigan State University, East Lansing, MI 48824, USA.

Corresponding author: Yan Li (email: yan.li@ncdenr.gov).

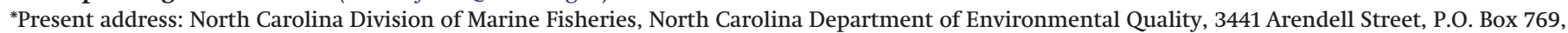
Morehead City, NC 28557-0769, USA.

Copyright remains with the author(s) or their institution(s). Permission for reuse (free in most cases) can be obtained from RightsLink. 
assessment models, such as the surplus production model and the statistical catch-at-age or length analysis, require catch data (Quinn and Deriso 1999). This lack of catch information, therefore, also becomes an important limiting factor in fisheries management and conservation because many recreational fisheries face a myriad of threats as a result of direct and indirect effects of changes in land use and climate (Dudgeon et al. 2006). Understanding these threats and what management actions might ameliorate these effects may benefit from the quantification of spatial and temporal variability of life-history traits, such as growth and mortality.

Smallmouth bass (Micropterus dolomieu) are an internationally important recreational fish species that is of high management and conservation interest. However, in some areas there have been concerns about the health of populations as a result of changing environmental conditions (Smith et al. 2015). For example, in Pennsylvania smallmouth bass support a valuable recreational fishery in the state, with smallmouth bass contributing $65 \%$ of the total angler catch from the Susquehanna River and its larger tributaries in 2007 (Smucker et al. 2010). The fishery is managed through size or creel limit, closed seasons, and habitat enhancement. Because spawning and the survival of young smallmouth bass are greatly influenced by environmental conditions, including temperature, flow, and dissolved oxygen concentrations (Rejwan et al. 1999; Lorantas et al. 2013), potential mortality, disease, and declines in abundance caused by stressful environmental conditions have been a concern of fishery management (Lorantas et al. 2013; Smith et al. 2015). As noted since 2005, the abundance of adult smallmouth bass in the Susquehanna and Juniata rivers in Pennsylvania has declined, likely in response to lower survival of young bass that were potentially a result of disease outbreaks (Lorantas et al. 2013). Water quality may also be a contributing factor to the observed disease and mortality events, including potential direct and indirect effects of endocrine disrupting compounds, herbicides, and pesticides (Blazer et al. 2014; Shull and Pulket 2015; Smith et al. 2015). Thus, there is an urgent need for understanding the spatial and temporal variability in life-history traits among smallmouth bass populations in Pennsylvania and identifying environmental factors that contribute to this variability. Although smallmouth bass ecology has been widely studied throughout North America (e.g., Beamesderfer and North 1995; MacRae and Jackson 2001), a comprehensive population assessment that provides the estimates of mortality and exploitation status has not been documented for any population and has not been performed for Pennsylvania populations. Like many recreational fisheries, the lack of catch information is a major limiting factor for conducting such assessments.

In this study, we established an approach for recreational fisheries that lack catch data. The approach incorporates available information into the catch-at-age or length analysis framework for estimating key parameters such as growth and mortality. With the approach applied to Pennsylvania smallmouth bass, we demonstrated that even with limited or no catch information, a comprehensive population assessment could still provide useful information for better understanding of the species and the fishery. Specifically, we aimed to (i) establish a comprehensive population assessment approach that incorporates length-age data, catch-per-unit-effort (CPUE) data, and young-of-year (YOY) data to estimate growth and mortality in the catch-at-length analysis framework using a hierarchical Bayesian approach; (ii) examine the spatial and temporal variability in growth and mortality of smallmouth bass; and (iii) explore the relationship of growth and mortality with water temperature and flow. Our study covered six populations of smallmouth bass that span a large spatial extent across Pennsylvania, and our approach can be extended to other freshwater recreational fish species that also have limited or no catch information.

\section{Methods}

Data

Our study covered six populations that support an economically important recreational smallmouth bass fishery in Pennsylvania (Fig. 1). The Allegheny River is located in the Ohio River basin and drains to the Mississippi River basin. The Susquehanna River with its branches (the North Branch, West branch; hereinafter referred to as North Susquehanna and West Susquehanna, respectively) and one of its major tributaries (the Juniata River) drains to the Atlantic Ocean through Chesapeake Bay and is the longest river on the east coast of the United States that drains to the Atlantic Ocean. The Delaware River drains to the Atlantic Ocean through the Delaware Bay. Among these six rivers, the Susquehanna River supports a world-class smallmouth bass fishery (Arway and Smith 2013).

The Pennsylvania Fish and Boat Commission (PFBC) has monitored and evaluated these rivers and their fisheries through fisheryindependent surveys. The smallmouth bass data for this study (i.e., the length-age data, 1986-2012; Table 1; the CPUE data (number of fish per hour, 1990-2013), and the YOY (age-0) data (number of fish per $50 \mathrm{~m}$ shoreline distance, 1991-2010)) were provided by the PFBC and were collected through these surveys. In the CPUE survey, fish were sampled predominately in July-September using nighttime flat-bottom boat electrofishing. The YOY were sampled using daytime backpack electrofishing techniques primarily during July and August. The length-age samples were primarily derived from electrofishing collections; however, other gears such as trap nets and gill nets also occasionally collected smallmouth bass in study waters. The age of individual fish was determined using scales.

\section{Growth analysis}

Our study included a growth analysis for estimating growth and a length-based analysis for estimating mortality (Fig. 2). In the growth analysis, we used the von Bertalanffy growth model to describe the individual growth for smallmouth bass (von Bertalanffy 1938):

$$
\begin{aligned}
& L_{i, j}=\left(L_{\infty, j}\left\{1-\exp \left[-K_{j}\left(t_{i, j}-t_{0, j}\right)\right]\right\}\right) \exp \left(\varepsilon_{L, i, j}\right) \\
& \varepsilon_{L, i, j} \sim \mathrm{N}\left(0, \sigma_{L, j}^{2}\right)
\end{aligned}
$$

where $j$ indexes the $j$ th river (or $j$ th population), $L_{\infty}$ is the asymptotic length (mm), $K$ is the annual growth coefficient (year ${ }^{-1}$ ), $t_{0}$ is the age at which a fish has a length of zero, and $L_{i}$ and $t_{i}$ are the length and age measured for each individual, respectively. We assumed the observed individual length $L_{i, j}$ followed a lognormal distribution and fit the von Bertalanffy growth model using a hierarchical Bayesian approach.

In this study, we explored two approaches to construct the priors for the growth parameters $\left(L_{\infty, j}, K_{j}\right.$, and $\left.t_{0, j}\right)$, both of which were hierarchically structured. In the first approach, we focused on the spatial variability in smallmouth bass growth by assuming the growth parameters varied across river but were constant over time. Specifically, we assumed the logarithm of river-specific parameters $L_{\infty, j}$ and $K_{j}$ followed a multivariate normal distribution (MVN), and $t_{0, j}$ followed a normal distribution, which were further governed by river-average parameters:

$$
\begin{aligned}
& {\left[\begin{array}{c}
\ln L_{\infty, j} \\
\ln K_{j}
\end{array}\right] \sim \operatorname{MVN}\left(\left[\begin{array}{c}
\ln \bar{L}_{\infty} \\
\ln \bar{K}
\end{array}\right], \Sigma\right)} \\
& t_{0, j} \sim \mathrm{N}\left(\bar{t}_{0}, \sigma_{t_{0}}^{2}\right)
\end{aligned}
$$

where $\bar{L}_{\infty}, \bar{K}$, and $\bar{t}_{0}$ are river-average parameters that describe the growth across rivers and follow a uniform distribution (Beamesderfer and North 1995). The standard deviation $\sigma_{t_{0}}$ was also uniformly distributed. The $\Sigma$ parameter denotes the variance-covariance matrix that was modeled with an inverse-Wishart distribution 
Fig. 1. Study rivers in Pennsylvania. Dots represent fixed stations sampled each year during 1990-2013. Rivers are plotted from left to right based on their geographical location from west to east in Pennsylvania. [Colour online.]

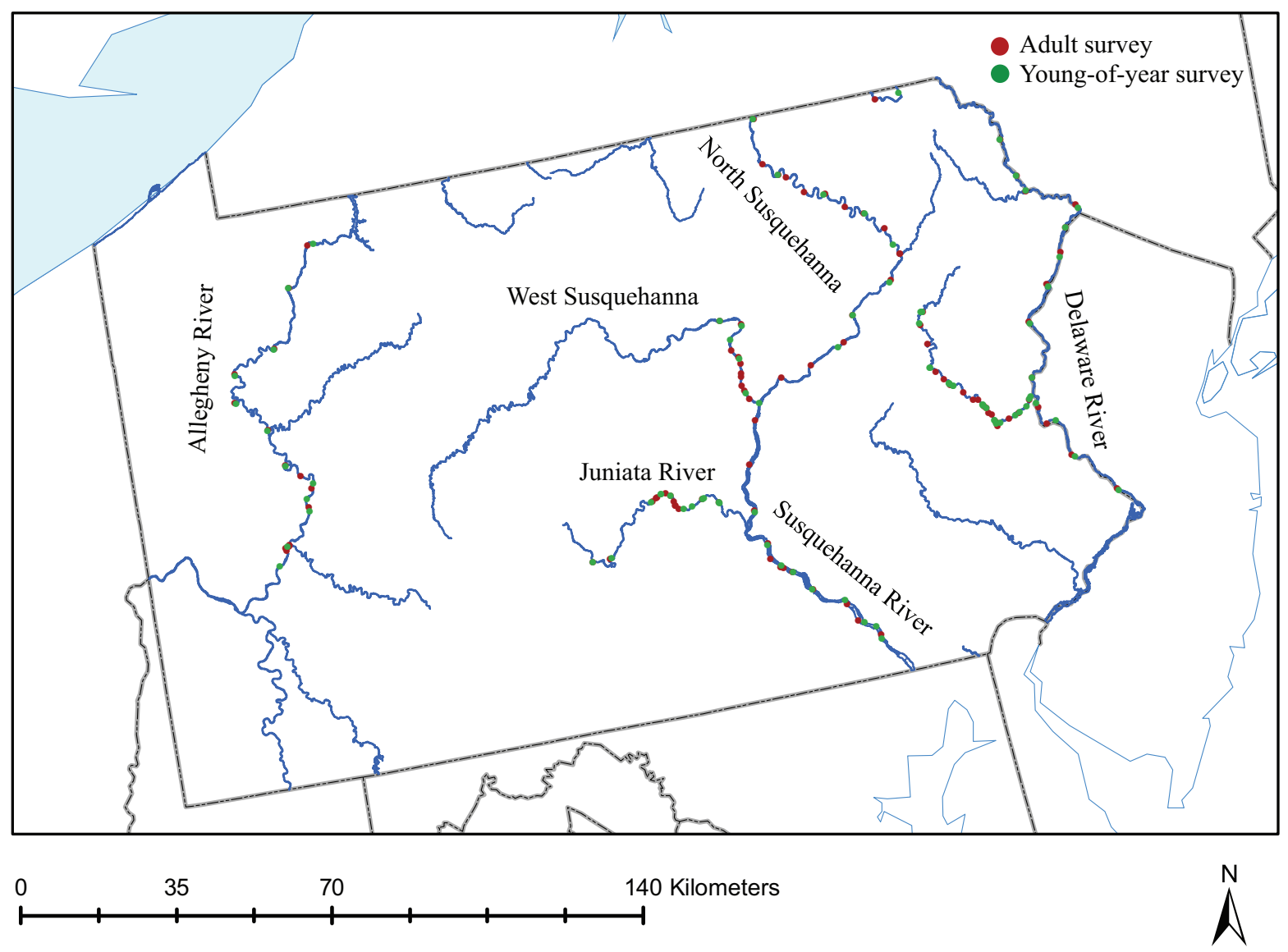

Table 1. Sample size of length-age data by year and river.

\begin{tabular}{lrrlrrrr}
\hline Year & Allegheny & Juniata & Susquehanna & $\begin{array}{l}\text { West } \\
\text { Susquehanna }\end{array}$ & Susquehanna & Delaware & Total \\
\hline 1986 & 374 & 154 & 470 & 98 & 502 & 313 & 1911 \\
1987 & 153 & 106 & 363 & 74 & 288 & 252 & 1236 \\
1988 & 39 & 425 & 382 & 75 & 448 & 0 & 1369 \\
1989 & 145 & 326 & 319 & 0 & 441 & 619 & 1850 \\
1990 & 773 & 400 & 475 & 189 & 682 & 504 & 3023 \\
1991 & 721 & 537 & 495 & 28 & 570 & 622 & 2973 \\
1992 & 659 & 497 & 548 & 208 & 773 & 512 & 3197 \\
1993 & 445 & 338 & 485 & 65 & 567 & 600 & 2500 \\
1994 & 66 & 641 & 432 & 86 & 580 & 593 & 2398 \\
1995 & 551 & 495 & 348 & 33 & 753 & 631 & 2811 \\
1996 & 764 & 147 & 131 & 48 & 0 & 256 & 1346 \\
1997 & 526 & 0 & 131 & 0 & 266 & 230 & 1153 \\
1998 & 123 & 182 & 178 & 24 & 416 & 143 & 1066 \\
1999 & 168 & 0 & 134 & 0 & 339 & 408 & 1049 \\
2000 & 167 & 0 & 177 & 0 & 281 & 354 & 979 \\
2001 & 0 & 0 & 212 & 0 & 0 & 0 & 212 \\
2004 & 57 & 0 & 0 & 0 & 0 & 0 & 57 \\
2005 & 204 & 150 & 199 & 36 & 121 & 165 & 875 \\
2006 & 508 & 303 & 182 & 0 & 437 & 577 & 2007 \\
2007 & 319 & 254 & 157 & 99 & 357 & 617 & 1803 \\
2008 & 292 & 248 & 404 & 110 & 354 & 467 & 1875 \\
2009 & 359 & 287 & 352 & 71 & 395 & 500 & 1964 \\
2010 & 220 & 429 & 460 & 80 & 417 & 569 & 2175 \\
2011 & 343 & 457 & 283 & 21 & 116 & 343 & 1563 \\
2012 & 320 & 321 & 323 & 28 & 461 & 213 & 1666 \\
Total & 8296 & 6697 & 7640 & 1373 & 9564 & 9488 & 43058 \\
\hline
\end{tabular}


Fig. 2. Schematic diagram for the model framework that includes a growth analysis and a length-based analysis. Refer to text for symbol explanation.

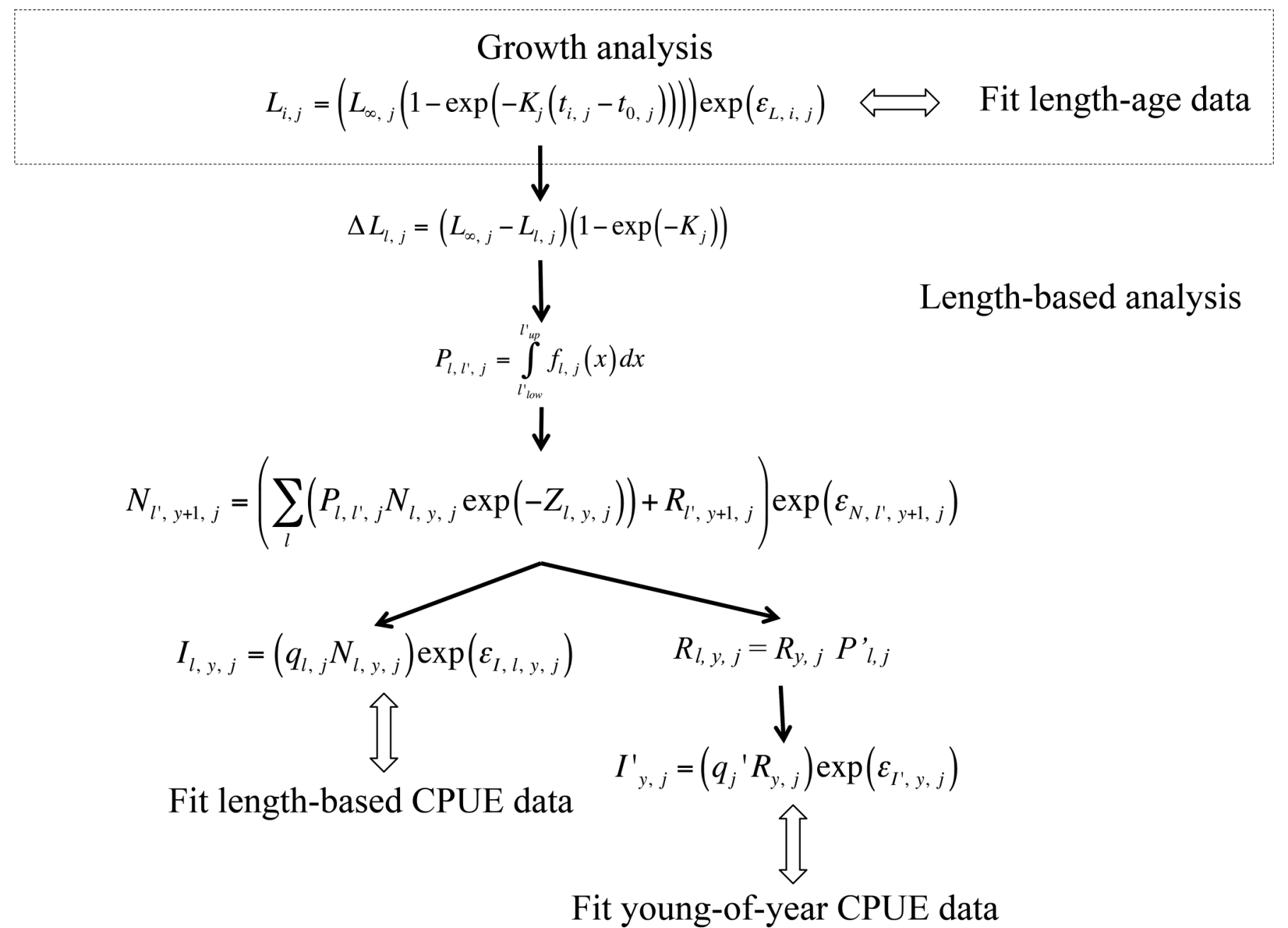

(Gelman and Hill 2007). Instead of modeling $L_{\infty}$ and $K$ independently, jointly modeling these two parameters with a negative correlation may improve model convergence because they are often highly negatively correlated due to model parameterization (Eveson et al. 2007; Kimura 2008; Midway et al. 2015). In the second approach, we assumed the growth parameters to vary both temporally and spatially and used a random-walk process to model the temporal variability in $L_{\infty, j}$ and $K_{j}$ :

$$
\begin{aligned}
& {\left[\begin{array}{c}
\ln L_{\infty, y+1, j} \\
\ln K_{y+1, j}
\end{array}\right] \sim \operatorname{MVN}\left(\left[\begin{array}{c}
\ln L_{\infty, y, j} \\
\ln K_{y, j}
\end{array}\right], \Sigma^{\prime}\right)} \\
& {\left[\begin{array}{c}
\ln L_{\infty, y=1, j} \\
\ln K_{y=1, j}
\end{array}\right] \sim \operatorname{MVN}\left(\left[\begin{array}{c}
\ln \bar{L}_{\infty} \\
\ln \bar{K}
\end{array}\right], \Sigma\right)}
\end{aligned}
$$

where $\bar{L}_{\infty}$ and $\bar{K}$ are river-average parameters for the first year growth and further follow a uniform distribution, and $\Sigma$ and $\Sigma^{\prime}$ are the variance-covariance matrices that further follow an inverseWishart distribution. The assumption on parameter $t_{0, j}$ in the second approach was the same as in the first approach.

The posterior distribution was obtained through the MetropolisHasting algorithm using Markov chain Monte Carlo (MCMC) simulation (Hilborn et al. 1994; Hoff 2009). We ran three concurrent chains with a total of 500000 iterations for each chain. We discarded the first 470000 iterations as burn-in and took every 10th of the remaining samples from each chain for analysis, which gives us a total of 9000 MCMC samples. We used JAGS (version 4.0.1) for the Bayesian analysis in this study. The joint posterior distribu- tion of $L_{\infty, j}$ and $K_{j}$ was used to develop the growth transition matrix for length-based analysis in the following section (Fig. 2).

\section{Length-based analysis}

We conducted a length-based model to estimate mortality for smallmouth bass (Fig. 2). The submodels were simultaneously fitted to match the observed length-structured CPUE data and the YOY data (age-0 CPUE data) using a Bayesian approach. With the length-based analysis, the population dynamics of smallmouth bass for each river were described in terms of the number of individuals at each size class over time (Sullivan et al. 1990):

$$
\begin{aligned}
& N_{l^{\prime}, y+1, j}=\left\{\sum_{l}\left[P_{l, l^{\prime}, j} N_{l, y, j} \exp \left(-Z_{l, y, j}\right)\right]+R_{l^{\prime}, y+1, j}\right\} \\
& \times \exp \left(\varepsilon_{N, l^{\prime}, y+1, j}\right) \\
& \varepsilon_{N, l^{\prime}, y+1, j} \sim \mathrm{N}\left(0, \sigma_{N, j}^{2}\right) \\
& I_{l, y, j}=\left(q_{l, j} N_{l, y, j}\right) \exp \left(\varepsilon_{I, l, y, j}\right) \\
& \varepsilon_{I, l, y, j} \sim \mathrm{N}\left(0, \sigma_{I, j}^{2}\right)
\end{aligned}
$$

where $j$ indexes the $j$ th river (or $j$ th population), $y$ indexes year $y, l$ and $l^{\prime}$ index the $l$ th and $l^{\prime}$ th length group, respectively, $N$ is the population size, $P_{l, l^{\prime}}$ represents the proportion of surviving individuals in length group $l$ that grows to all length groups $l^{\prime}$ during 1 year, $Z$ is instantaneous total mortality, $R$ is the recruitment, $I$ is the abundance index (i.e., CPUE), $q$ is the catchability coefficient, $\varepsilon$ denotes process or observation error, and $\mathrm{N}\left(0, \sigma^{2}\right)$ denotes the 
normal distribution with mean zero and a standard deviation $\sigma$. In the model, we assumed the variation in population size $\sigma_{N, j}$ to have a hierarchical prior that centered around a river-average parameter $\bar{\sigma}_{\mathrm{N}}$ :

$$
\sigma_{N, j}=\left(\bar{\sigma}_{N}\right) \exp \left(\varepsilon_{\sigma_{N, j}}\right) ; \quad \varepsilon_{\sigma_{N, j}} \sim \mathrm{N}\left(0, \sigma_{\sigma_{N}}^{2}\right)
$$

where the river-average parameters $\bar{\sigma}_{N}$ and standard deviations $\sigma_{\sigma_{N}}$ further followed a uniform distribution.

\section{Growth transition}

The observed length of smallmouth bass in the surveys ranged from 25 to $538 \mathrm{~mm}$, and the catch data were recorded by $25 \mathrm{~mm}$ length groups. Thus, in the model, we set the minimum length and the maximum length to be 25 and $550 \mathrm{~mm}$, respectively. We constructed a total of seven length groups based on the life history of smallmouth bass. Based on a sample of 58 smallmouth bass from Bald Eagle Creek, Pennsylvania, and 68 smallmouth bass from the Juniata River that were collected in 1986, all bass less than $175 \mathrm{~mm}$ were immature and all individuals over $225 \mathrm{~mm}$ were mature (Hoopes 1987). Therefore, in the model the first three length groups ranged from 25 to $75 \mathrm{~mm}$, from 75.1 to $125 \mathrm{~mm}$, and from 125.1 to $175 \mathrm{~mm}$, respectively, which encompassed the length at age-0 and likely immature. The fourth length group ranged from 175.1 to $225 \mathrm{~mm}$ containing fish that were mostly immature. The legal harvest size for smallmouth bass is $305 \mathrm{~mm}$ under PFBC general regulation and $381 \mathrm{~mm}$ for cold weather periods (Lorantas et al. 2013). Thus, we used the length group 225.1$300 \mathrm{~mm}$ to represent young adults before reaching harvestable size and the length groups $300.1-375 \mathrm{~mm}$ and $375.1-550 \mathrm{~mm}$ for the last two length groups, which contained harvestable-sized fish. The model described the population dynamics of smallmouth bass in terms of the number of individuals at each length group over time.

To determine the growth transition proportion $P_{l, l^{\prime}}$, we used the Monte Carlo simulation approach (Chen et al. 2003). Using the joint posterior distribution of $L_{\infty, j}$ and $K_{j}$ that we obtained by fitting the von Bertalanffy growth model in the Growth analysis section of the Methods, we derived the probability distribution $f_{l, j}($.$) of the annual length increment \left(\mathrm{mm}, \Delta L_{l, j}\right)$ for each length group $l$ by calculating the following (von Bertalanffy 1938; Gulland 1983):

$$
\Delta L_{l, j}=\left(L_{\infty, j}-L_{l, j}\right)\left[1-\exp \left(-K_{j}\right)\right]
$$

where $L_{l}$ denotes the midlength of length group $l$. The growth transition proportion from length group $l$ to length group $l^{\prime}$ was then calculated as

$$
P_{l, l^{\prime}, j}=\int_{l_{\text {low }}^{\prime}}^{l_{\text {lup }}^{\prime}} f_{l, j}(x) d x
$$

where $l_{\mathrm{up}}^{\prime}$ and $l_{\mathrm{low}}^{\prime}$ are the upper and lower ends, respectively, of length group $l^{\prime}$. Negative growth was not permitted in this study, and thus we constrained $l^{\prime} \geq l$ and $\sum P_{l, l^{\prime}, j}=1$. We assumed the last length group to be a plus group with all the individuals staying in the same length group and only subject to mortality.

\section{Mortality}

In Pennsylvania smallmouth bass recreational fisheries, a bass must be at least $305 \mathrm{~mm}$ to be legally harvested (Lorantas et al. 2013). In the model, we assumed that the fish in the first five length groups (i.e., 25-75, 75.1-125, 125.1-175, 175.1-225, and 225.1-

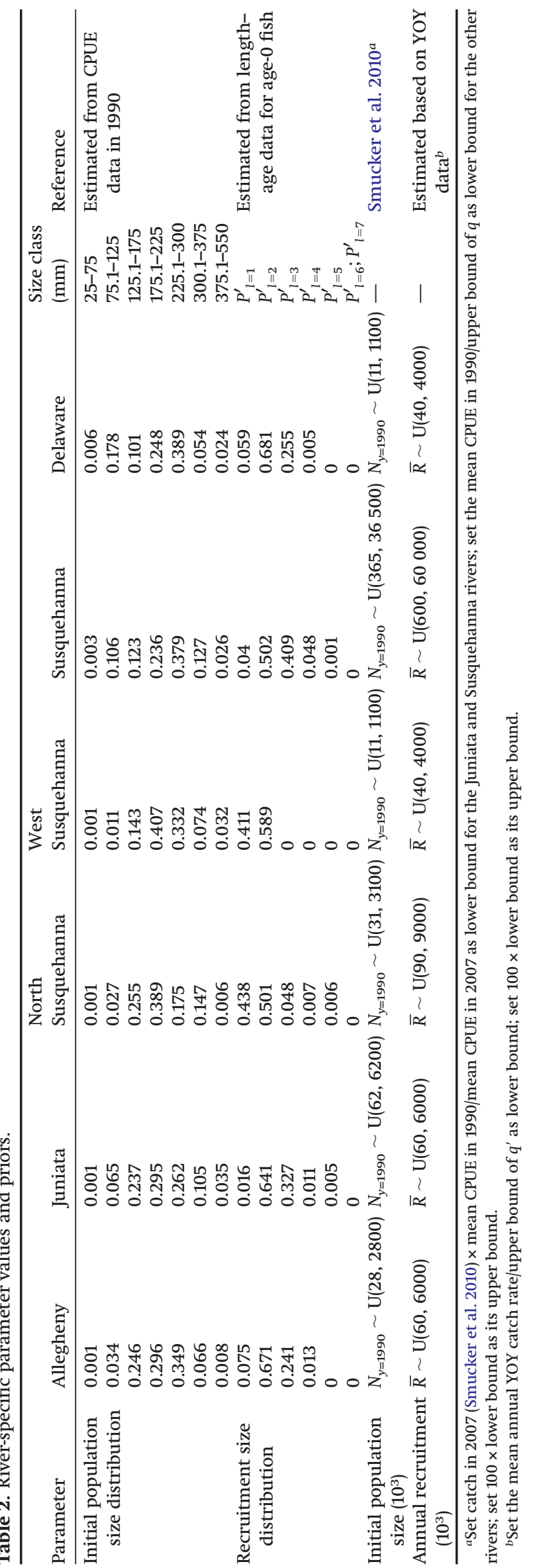

- Published by NRC Research Press 
$300 \mathrm{~mm}$ ) were not subject to fishing mortality, and thus, their total mortality $(Z)$ equaled their natural mortality $(M)$. We assumed the natural mortality for fish in the first three length groups, representing the natural mortality for YOY (age- $0, M_{Y O Y}$ ), to be constant over length and an unknown parameter to estimate (i.e., $Z_{l=1,2,3}=M_{\text {YoY) }}$. We treated the natural mortality for fish in the fourth and fifth length groups, representing juvenile $\left(M_{\mathrm{JUV}}\right)$ and young adult mortality $\left(M_{\text {YOUNG }}\right)$, respectively, as an unknown parameter to estimate (i.e., $Z_{l=4}=M_{\mathrm{JUV}}$ and $Z_{l=5}=M_{\text {YOUNG }}$ ). Owing to lack of catch information, it is difficult to separate fishing mortality and natural mortality during parameter estimation for adult bass. Angling is practiced in the smallmouth bass recreational fishery in Pennsylvania, and thus we assumed that the gear selectivity was one for all adult fish that are subject to fishing. In the model, we set the total mortality for fish in the last two length groups (300.1-550 mm), representing the total mortality for adults $\left(Z_{\mathrm{ADU}}\right)$, to be a constant over length and an unknown parameter to estimate (i.e., $Z_{l=6,7}=Z_{\mathrm{ADU}}$ ).

Similar to the growth analysis above, we explored both the spatial and temporal variability in mortality by constructing two types of hierarchical priors. The first type of priors assumed that the river-specific mortality did not vary over time but varied across rivers and followed a lognormal distribution governed by the river-average parameters:

$$
\begin{aligned}
& M_{\mathrm{YOY}, j}=\left(\bar{M}_{\mathrm{YOY}}\right) \exp \left(\varepsilon_{\mathrm{YOY}, j}\right) ; \quad \varepsilon_{\mathrm{YOY}, j} \sim \mathrm{N}\left(0, \sigma_{\mathrm{YOY}}^{2}\right) \\
& M_{\mathrm{JUV}, j}=\left(\bar{M}_{\mathrm{JUV}}\right) \exp \left(\varepsilon_{\mathrm{JUV}, j}\right) ; \quad \varepsilon_{\mathrm{JUV}, j} \sim \mathrm{N}\left(0, \sigma_{\mathrm{JUV}}^{2}\right) \\
& M_{\mathrm{YOUNG}, j}=\left(\bar{M}_{\mathrm{YOUNG}}\right) \exp \left(\varepsilon_{\mathrm{YOUNG}, j}\right) ; \quad \varepsilon_{\mathrm{YOUNG}, j} \sim \mathrm{N}\left(0, \sigma_{\mathrm{YOUNG}}^{2}\right) \\
& Z_{\mathrm{ADU}, j}=\left(\bar{Z}_{\mathrm{ADU}}\right) \exp \left(\varepsilon_{\mathrm{ADU}, j}\right) ; \quad \varepsilon_{\mathrm{ADU}, j} \sim \mathrm{N}\left(0, \sigma_{\mathrm{ADU}}^{2}\right)
\end{aligned}
$$

where the river-average parameters $\bar{M}_{\mathrm{YOY}}, \bar{M}_{\mathrm{JUV}}, \bar{M}_{\mathrm{YOUNG}}$, and $\bar{Z}_{\mathrm{ADU}}$ and the standard deviations $\sigma_{\mathrm{YOY}}, \sigma_{\mathrm{JUV}}, \sigma_{\mathrm{YOUNG}}$, and $\sigma_{\mathrm{ADU}}$ further followed a uniform distribution (Rose 2005; Allen et al. 2008; Zipkin et al. 2008). The second type of priors assumed mortality varied both spatially and temporally, and the annual mortality followed a random-walk process for each river:

$$
\begin{aligned}
& M_{\mathrm{YOY}, y+1, j}=\left(M_{\mathrm{YOY}, y, j}\right) \exp \left(\varepsilon_{\mathrm{YOY}, y+1, j}\right) ; \quad \varepsilon_{\mathrm{YOY}, y+1, j} \sim \mathrm{N}\left(0, \sigma_{\mathrm{YOY}, j}^{\prime 2}\right) \\
& M_{\mathrm{JUV}, y+1, j}=\left(M_{\mathrm{JUV}, y, j}\right) \exp \left(\varepsilon_{\mathrm{JUV}, y+1, j}\right) ; \quad \varepsilon_{\mathrm{JUV}, y+1, j} \sim \mathrm{N}\left(0, \sigma_{\mathrm{JUV}, j}^{\prime 2}\right) \\
& M_{\text {YOUNG }, y+1, j}=\left(M_{\text {YOUNG }, y, j}\right) \exp \left(\varepsilon_{\text {YOUNG }, y+1, j}\right) \text {; } \\
& \varepsilon_{\mathrm{YOUNG}, y+1, j} \sim \mathrm{N}\left(0, \sigma_{\mathrm{YOUNG}, j}^{\prime 2}\right) \\
& Z_{\mathrm{ADU}, y+1, j}=\left(\mathrm{Z}_{\mathrm{ADU}, y, j}\right) \exp \left(\varepsilon_{\mathrm{ADU}, y+1, j}\right) ; \quad \varepsilon_{\mathrm{ADU}, y+1, j} \sim \mathrm{N}\left(0, \sigma_{\mathrm{ADU}, j}^{\prime 2}\right) \\
& M_{\mathrm{YOY}, y=1, j}=\left(\bar{M}_{\mathrm{YOY}}\right) \exp \left(\varepsilon_{\mathrm{YOY}, y=1, j}\right) ; \quad \varepsilon_{\mathrm{YOY}, y=1, j} \sim \mathrm{N}\left(0, \sigma_{\mathrm{YOY}}^{2}\right) \\
& M_{\mathrm{JUV}, y=1, j}=\left(\bar{M}_{\mathrm{JUV}}\right) \exp \left(\varepsilon_{\mathrm{JUV}, y=1, j}\right) ; \quad \varepsilon_{\mathrm{JUV}, y=1, j} \sim \mathrm{N}\left(0, \sigma_{\mathrm{JUV}}^{2}\right) \\
& M_{\text {YOUNG }, y=1, j}=\left(\bar{M}_{\text {YOUNG }}\right) \exp \left(\varepsilon_{\text {YOUNG }, y=1, j}\right) \text {; } \\
& \varepsilon_{\text {YOUNG }, y=1, j} \sim \mathrm{N}\left(0, \sigma_{\text {YOUNG }}^{2}\right) \\
& Z_{\mathrm{ADU}, y=1, j}=\left(\bar{Z}_{\mathrm{ADU}}\right) \exp \left(\varepsilon_{\mathrm{ADU}, y=1, j}\right) ; \quad \varepsilon_{\mathrm{ADU}, y=1, j} \sim \mathrm{N}\left(0, \sigma_{\mathrm{ADU}}^{2}\right)
\end{aligned}
$$

where $\bar{M}_{\mathrm{YOY}}, \bar{M}_{\mathrm{JUV}}, \bar{M}_{\mathrm{YOUNG}}$, and $\bar{Z}_{\mathrm{ADU}}$ are river-average mortalities for the first year, and they further followed a uniform distribution. The standard deviations $\sigma_{\mathrm{YOY}}, \sigma_{\mathrm{JUV}}, \sigma_{\mathrm{YOUNG}}$, and $\sigma_{\mathrm{ADU}}$ were also uniformly distributed. We further assumed the annual variation in mortality for each river $\left(\sigma_{\mathrm{YOY}, j}^{\prime}, \sigma_{\mathrm{JUV}, j}^{\prime}, \sigma_{\mathrm{YOUNG}, j}^{\prime}\right.$, and $\left.\sigma_{\mathrm{ADU}, j}^{\prime}\right)$ followed a lognormal distribution with a river-average mean $\left(\bar{\sigma}_{\mathrm{YOY}}^{\prime}, \bar{\sigma}_{\mathrm{JUV}}^{\prime}, \bar{\sigma}_{\mathrm{YOUNG}}^{\prime}\right.$, and $\left.\bar{\sigma}_{\mathrm{ADU}}^{\prime}\right)$ and a uniformly distributed standard deviation $\left(\sigma_{\sigma_{\mathrm{YOY}}^{\prime}}, \sigma_{\sigma_{\mathrm{JUV}}^{\prime}}, \sigma_{\sigma_{\mathrm{YOUNG}}^{\prime}}\right.$, and $\left.\sigma_{\sigma_{\mathrm{ADU}}^{\prime}}\right)$ :

$$
\begin{aligned}
& \sigma_{\mathrm{YOY}, j}^{\prime}=\left(\bar{\sigma}_{\mathrm{YOY}}^{\prime}\right) \exp \left(\varepsilon_{\sigma_{\mathrm{YOY}}^{\prime}}\right) ; \quad \varepsilon_{\sigma_{\mathrm{YOY}}^{\prime}} \sim \mathrm{N}\left(0, \sigma_{\sigma_{\mathrm{YOY}}^{\prime}}^{2}\right) \\
& \sigma_{\mathrm{JUV}, j}^{\prime}=\left(\bar{\sigma}_{\mathrm{JUV}}^{\prime}\right) \exp \left(\varepsilon_{\sigma_{\mathrm{JUV}}^{\prime}}\right) ; \quad \varepsilon_{\sigma_{\mathrm{JUV}}^{\prime}} \sim \mathrm{N}\left(0, \sigma_{\sigma_{\mathrm{JUV}}^{\prime}}^{2}\right) \\
& \sigma_{\mathrm{YOUNG}, j}^{\prime}=\left(\bar{\sigma}_{\mathrm{YOUNG}}^{\prime}\right) \exp \left(\varepsilon_{\sigma_{\mathrm{YOUNG}}^{\prime}}\right) ; \quad \varepsilon_{\sigma_{\mathrm{YOUNG}}^{\prime}} \sim \mathrm{N}\left(0, \sigma_{\sigma_{\mathrm{YOUNG}}^{\prime}}^{2}\right) \\
& \sigma_{\mathrm{ADU}, j}^{\prime}=\left(\bar{\sigma}_{\mathrm{ADU}}^{\prime}\right) \exp \left(\varepsilon_{\sigma_{\mathrm{ADU}}^{\prime}}\right) ; \quad \varepsilon_{\sigma_{\mathrm{ADU}}^{\prime}} \sim \mathrm{N}\left(0, \sigma_{\sigma_{\mathrm{ADU}}^{\prime}}^{2}\right)
\end{aligned}
$$

\section{Recruitment}

In our model, assuming the age- 0 fish to be the recruitment, the length-based annual recruitment (the recruitment of age-0 fish) $R_{l, y, j}$ was separated into a temporal component $R_{y, j}$ and a lengthbased component $P_{l, j}^{\prime}$ (Sullivan et al. 1990):

$$
R_{l, y, j}=R_{y, j} P_{l, j}^{\prime}
$$

where the proportion of age- 0 fish at the lth length group $P_{l, j}^{\prime}$ was estimated using the length distribution data for age-0 fish at each river. The spawner size can often only explain a small amount of the high variation in recruitment. Thus, in the model we directly estimated the annual recruitment at each river $R_{y, j}$ to avoid assuming a fixed spawner-recruitment relationship (Jiao et al. 2012):

$$
\begin{aligned}
R_{y, j} & =\left(\bar{R}_{j}\right) \exp \left(\varepsilon_{R, j}\right) \\
\varepsilon_{R, j} & \sim \mathrm{N}\left(0, \sigma_{R, j}^{2}\right) \\
I_{y, j}^{\prime} & =\left(q_{j}^{\prime} R_{y, j}\right) \exp \left(\varepsilon_{I^{\prime}, y, j}\right) \\
\varepsilon_{I^{\prime}, y, j} & \sim \mathrm{N}\left(0, \sigma_{I^{\prime}, j}^{2}\right)
\end{aligned}
$$

where annual recruitment for each river $R_{y, j}$ was assumed to follow a lognormal distribution centered around $\bar{R}_{j}$ that further followed a uniform distribution; each river has its own $\bar{R}_{\mathrm{j}}$ and priors for $\bar{R}_{j}$ and is not linked to other rivers in the model; $I^{\prime}$ is the age- 0 abundance index (i.e., age-0 CPUE), and $q^{\prime}$ is the catchability of age-0 fish; we used a hierarchical prior for the variation in annual recruitment $\sigma_{R, j}$ that followed a lognormal distribution centered around a river-average parameter $\bar{\sigma}_{R}$ :

$$
\sigma_{R, j}=\left(\bar{\sigma}_{R}\right) \exp \left(\varepsilon_{\sigma_{R, j}}\right) ; \quad \varepsilon_{\sigma_{R, j}} \sim \mathrm{N}\left(0, \sigma_{\sigma_{R}}^{2}\right)
$$

where the river-average parameters $\bar{\sigma}_{R}$ and its standard deviations $\sigma_{\sigma_{\sigma}}$ further followed a uniform distribution. We used the same MCMC procedure in this length-based analysis as in the growth analysis. Parameter values and priors used in this analysis are listed in Tables 2 and 3. Examples of posterior distributions of key parameters from the models assuming growth and mortality parameters vary both spatially and temporally are shown in the online Supplementary material (Fig. S1 ${ }^{1}$ ).

\section{Relationship of growth and mortality estimates with environmental factors}

Smallmouth bass have a life history that is sensitive to environmental conditions (Rejwan et al. 1999; Arway and Smith 2013; Lorantas et al. 2013). In this study, we explored the relationships of growth and mortality with the water temperature and monthly flow during spawning season (April-June) because smallmouth bass YOY are sensitive to thermal stress and flow (Shuter et al. 1980; Goff 1985; Lukas and Orth 1995; Rejwan et al. 1999; Lorantas et al. 2013). For each environmental factor, a time series of estimated growth $\left(\ln \left(L_{\infty}\right)\right.$ or $\left.\ln (K)\right)$ or mortality $\left(\ln \left(M_{\mathrm{YOY}}\right), \ln \left(M_{\mathrm{JUV}}\right)\right.$, $\ln \left(M_{\text {YOUNG }}\right)$, or $\left.\ln \left(Z_{\mathrm{ADU}}\right)\right)$ was regressed against this single environmental factor using a simple linear regression model; we repeated this regression analysis for each of the 9000 time series obtained from the joint posterior distribution that was estimated by assum-

${ }^{1}$ Supplementary data are available with the article through the journal Web site at http://nrcresearchpress.com/doi/suppl/10.1139/cjfas-2017-0052. 
Table 3. Parameter values and priors used across rivers.

\begin{tabular}{|c|c|c|}
\hline Parameters & Values & Reference \\
\hline Asymptotic length (mm) & $\bar{L}_{\infty} \sim \mathrm{U}(538,1700)$ & Beamesderfer and North 1995 \\
\hline Growth coefficient (year ${ }^{-1}$ ) & $\overline{\mathrm{K}} \sim \mathrm{U}(0.01,0.5)$ & Beamesderfer and North 1995 \\
\hline Age at zero length (year) & $\bar{t}_{0} \sim \mathrm{U}(-2,0)$ & \\
\hline Standard deviation of $t_{0}$ & $\sigma_{t_{0}} \sim \mathrm{U}(0.001,10)$ & \\
\hline Young-of-year (YOY) natural mortality (year-1) & $\bar{M}_{\mathrm{YOY}} \sim \mathrm{U}(0.2,0.8)$ & Rose 2005; Zipkin et al. 2008 \\
\hline Juvenile natural mortality (year-1) & $\bar{M}_{\mathrm{JUV}} \sim \mathrm{U}(0.2,0.8)$ & Rose 2005; Zipkin et al. 2008 \\
\hline Standard deviation of initial year mortality & $\sigma_{\mathrm{YOY}}, \sigma_{\mathrm{JUV}}, \sigma_{\mathrm{YOUNG}}, \sigma_{\mathrm{ADU}} \sim \mathrm{U}(0.001,1)$ & \\
\hline Mean of the annual mortality variation & $\bar{\sigma}_{\mathrm{YOY}}^{\prime}, \bar{\sigma}_{\mathrm{JUV}}^{\prime}, \bar{\sigma}_{\mathrm{YOUNG}}^{\prime}, \bar{\sigma}_{\mathrm{ADU}}^{\prime} \sim \mathrm{U}(0.001,1)$ & \\
\hline Standard deviation of the annual mortality variation & $\sigma_{\sigma_{\mathrm{YOY}}}, \sigma_{\sigma_{\mathrm{JUV}}}, \sigma_{\sigma_{\mathrm{YOUNG}}}, \sigma_{\sigma_{\mathrm{ADU}}} \sim \mathrm{U}(0.001,1)$ & \\
\hline Mean of the variation in log-population size & $\bar{\sigma}_{N} \sim \mathrm{U}(0.001,10)$ & \\
\hline Standard deviation of the variation in log-population size & $\sigma_{\sigma_{N}} \sim \mathrm{U}(0.001,10)$ & \\
\hline Standard deviation of log-YOY catch rate & $\sigma_{I^{\prime}} \sim \mathrm{U}(0.001,10)$ & \\
\hline
\end{tabular}

ing spatial and temporal variations in growth and mortality. We presented the percentage of regressions (among the total of 9000 regressions) that have a significant slope estimate ( $p$ value $<0.05$ ). Flow data were available from the US Geological Survey (http:// waterdata.usgs.gov). Water temperature data were provided by Pennsylvania Department of Environmental Protection.

\section{Results}

\section{Spatial and temporal variability in growth}

The growth estimates were substantially different across most rivers (Fig. 3). The growth in the Allegheny and Juniata rivers were similar, with larger $L_{\infty}$ estimates (mean $=1438 \mathrm{~mm}$ and $95 \% \mathrm{CI}=$ 1141-1895 $\mathrm{mm}$ for the Allegheny River; mean $=1347 \mathrm{~mm}$ and 95\% CI = 1216-1499 $\mathrm{mm}$ for the Juniata River) and smaller $\mathrm{K}$ estimates (mean $=0.039$ and $95 \% \mathrm{CI}=0.028-0.05$ for the Allegheny River; mean $=0.041$ and $95 \% \mathrm{CI}=0.037-0.046$ for the Juniata River) compared with other rivers (Fig. 3). The growth estimates for the North Susquehanna and West Susquehanna rivers were moderate, with $L_{\infty}=797 \mathrm{~mm}(95 \% \mathrm{CI}=726-877 \mathrm{~mm})$ and $L_{\infty}=618 \mathrm{~mm}$ $(95 \% \mathrm{CI}=560-688 \mathrm{~mm})$, respectively, and $K=0.097(95 \% \mathrm{CI}=$ $0.086-0.109)$ and $K=0.1487(95 \% \mathrm{CI}=0.124-0.171)$, respectively. The Susquehanna River produced the smallest $L_{\infty}$ estimate (mean $=475 \mathrm{~mm}$ and $95 \% \mathrm{CI}=463-487 \mathrm{~mm})$ and the largest $\mathrm{K}$ estimate $($ mean $=0.21$ and $95 \% \mathrm{CI}=0.199-0.22$ ). The $L_{\infty}$ in the Allegheny River and the $K$ estimate in the West Susquehanna River were estimated with relatively high uncertainty (Fig. 3) resulting from limited data for old fish in the Allegheny River and limited data for young fish in the West Susquehanna River, respectively (Fig. 4). Low uncertainty occurred in growth estimation for young fish with abundant data, and high uncertainty occurred for old fish with sparse data (Fig. 4). The growth of older fish ( $>10$ years old) in the Juniata and Susquehanna rivers were estimated with lower uncertainty than in other rivers due to more abundant data for older fish in these two rivers.

Growth estimates of smallmouth bass varied significantly over time with different temporal patterns across rivers (Fig. 5). Smallmouth bass in most rivers had smaller $L_{\infty}$ estimates and faster growth rate $K$ after 2005, except those in the Delaware River whose estimated growth fluctuated between 364 and $750 \mathrm{~mm}$ on average in $L_{\infty}$ and between 0.136 and 0.331 on average in $K$. Smallmouth bass in all rivers, except the Delaware River, showed a peak in $L_{\infty}$ estimates and a sharp drop in growth rate $(K)$ estimates between 1987 and 1989. Annual estimates of growth parameters for years having limited data were associated with high uncertainty (Fig. 5).

\section{Spatial and temporal variability in mortality}

The estimated mortality showed less spatial variability for YOY, juveniles, and young adults than for adults, represented by their overlapping 95\% CIs (Fig. 6). The Susquehanna River yielded the highest YOY natural mortality and the largest uncertainty (mean = 0.33 and $95 \% \mathrm{CI}=0.05-0.92$ ). Smallmouth bass in the Susquehanna and Delaware rivers had relatively higher young adult natural mortality (mean $=0.6$ for the Susquehanna River; mean = 1.04 for the Delaware River) and significantly lower adult total mortality (mean $=0.11$ for both rivers) than other rivers.

The YOY mortality estimates for the Allegheny, Susquehanna, and Delaware rivers started to increase beginning in 2000, among which the Susquehanna River had the highest estimates (mean = $0.28-0.89$ ) and the greatest increase since 2000 (approximately $96 \%$ increase when comparing the averages of posterior means before and after 2000; Fig. 7). The YOY mortality estimates for the Juniata and North Susquehanna rivers varied little over time, and those for the West Susquehanna River started to decrease in 1997. The annual patterns of juvenile and young adult mortality estimates were similar for each river except for the Delaware River, with both estimates declining over time for the Juniata River, Susquehanna River, and its north and west branches and with both estimates beginning to rise around 2000 for the Alleghany River (Fig. 7). The estimated juvenile mortality for smallmouth bass in the Delaware River slowly increased beginning in 1995, whereas its young adult mortality demonstrated a declining trend over time. The estimated adult mortality started to decline in 2007 for the Delaware River and around 2000 for the other five rivers. Before this decline, the adult mortality estimates remained high (mean $=0.91-2.13)$ for the Allegheny and the North and West Susquehanna rivers, whereas for the other three rivers, they became low during the early modeled time period ( mean $=0.25-0.66$ during the first 3-4 years for the Juniata and Susquehanna rivers and mean $=0.44-0.98$ during the first 10 years for the Delaware River) and were then followed by a peak (mean $=1.95-2.23)$. The juvenile and young adult mortalities were estimated with larger uncertainty than the YOY and adult mortalities for most rivers. 
Fig. 3. Estimated growth parameters (asymptotic length $L_{\infty}(\mathrm{mm})$ and annual growth coefficient $K$ (year-1)) from the growth analysis assuming growth parameters to vary spatially but remain constant temporally. Dots represent posterior means, and bars represent $95 \%$ credible intervals.
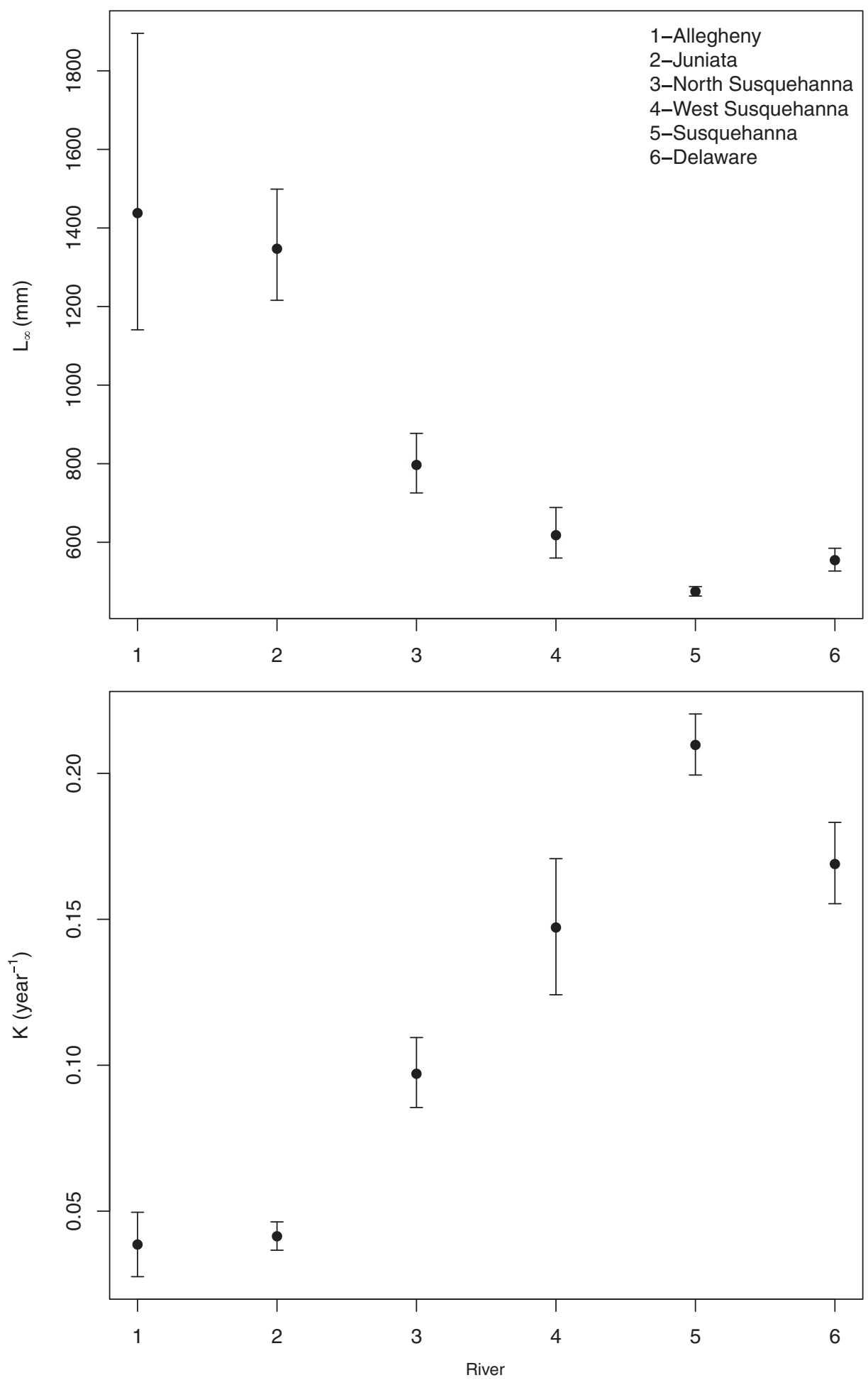

The YOY mortality estimates for smallmouth bass in Susquehanna River and the adult mortality estimates in the North and West Susquehanna rivers were associated with higher uncertainty than other rivers.

The fitted CPUE and YOY catch rate from both length-based analysis (i.e., the one assuming only spatial variability in mortality and the other assuming both temporal and spatial variability) were sim- ilar. Thus, we only show the fitted results from the latter because it better captured the temporal pattern in observed data with the additional assumption of temporally varying mortality (Fig. 8). Great uncertainty was always associated with the CPUE or YOY catch rate estimates in the years with limited observations. Estimated CPUE and YOY catch rate for the West Susquehanna River had higher uncertainty than most estimates for other rivers. The CPUE of small 
Fig. 4. Fitted von Bertalanffy growth model from the growth analysis assuming growth parameters to vary spatially but remain constant temporally. Black solid lines represent posterior means, grey shaded areas represent $95 \%$ credible intervals, and red rectangles represent observed length-age data. [Colour online.]
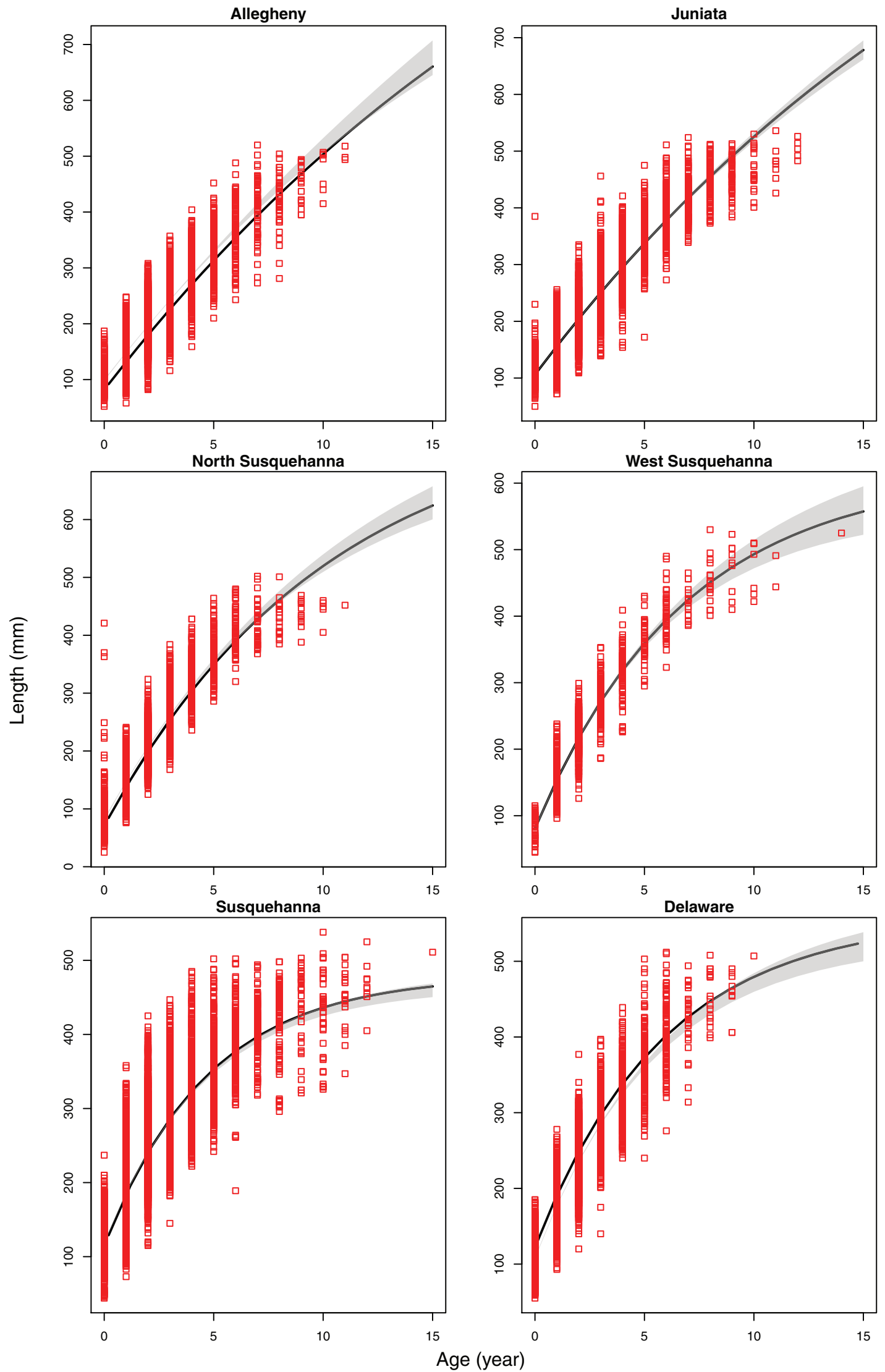

$\downarrow$ Published by NRC Research Press 
Fig. 5. Estimated growth parameters (asymptotic length $L_{\infty}(\mathrm{mm})$ and annual growth coefficient $K$ (year ${ }^{-1}$ )) from the growth analysis assuming growth parameters to vary both spatially and temporally. Black solid lines represent posterior means, and grey shaded areas represent $95 \%$ credible intervals.
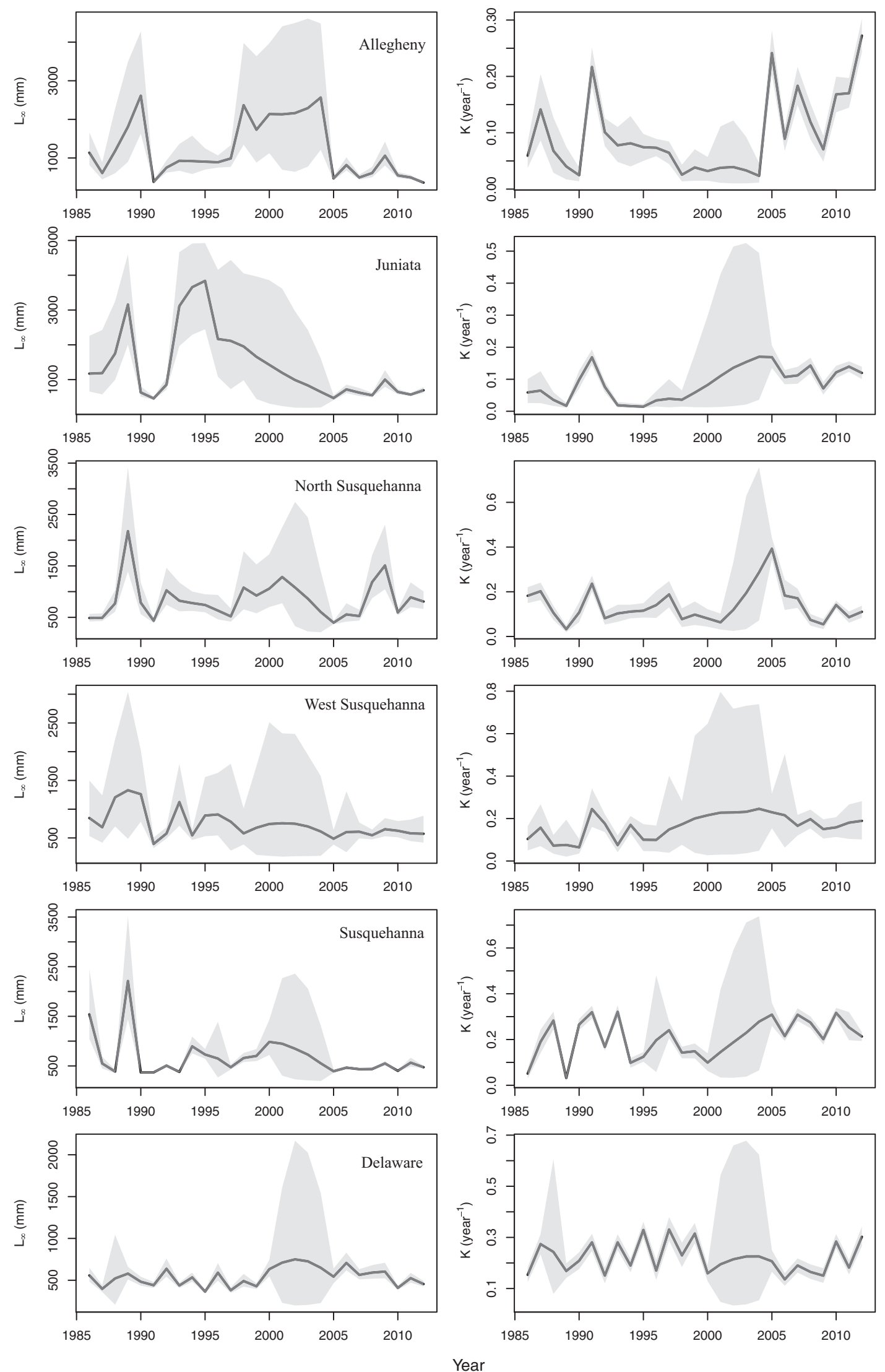

\ Published by NRC Research Press 
Fig. 6. Estimated mortality parameters (young-of-year: $M_{\mathrm{YOY}}$; juveniles: $M_{\mathrm{JUV}}$; young adults: $M_{\mathrm{YOUNG}}$ : and adults: $Z_{\mathrm{ADU}}$ ) (year-1) from the length-based analysis assuming mortality parameters vary spatially but remain constant temporally. Dots represent posterior means, and bars represent $95 \%$ credible intervals.
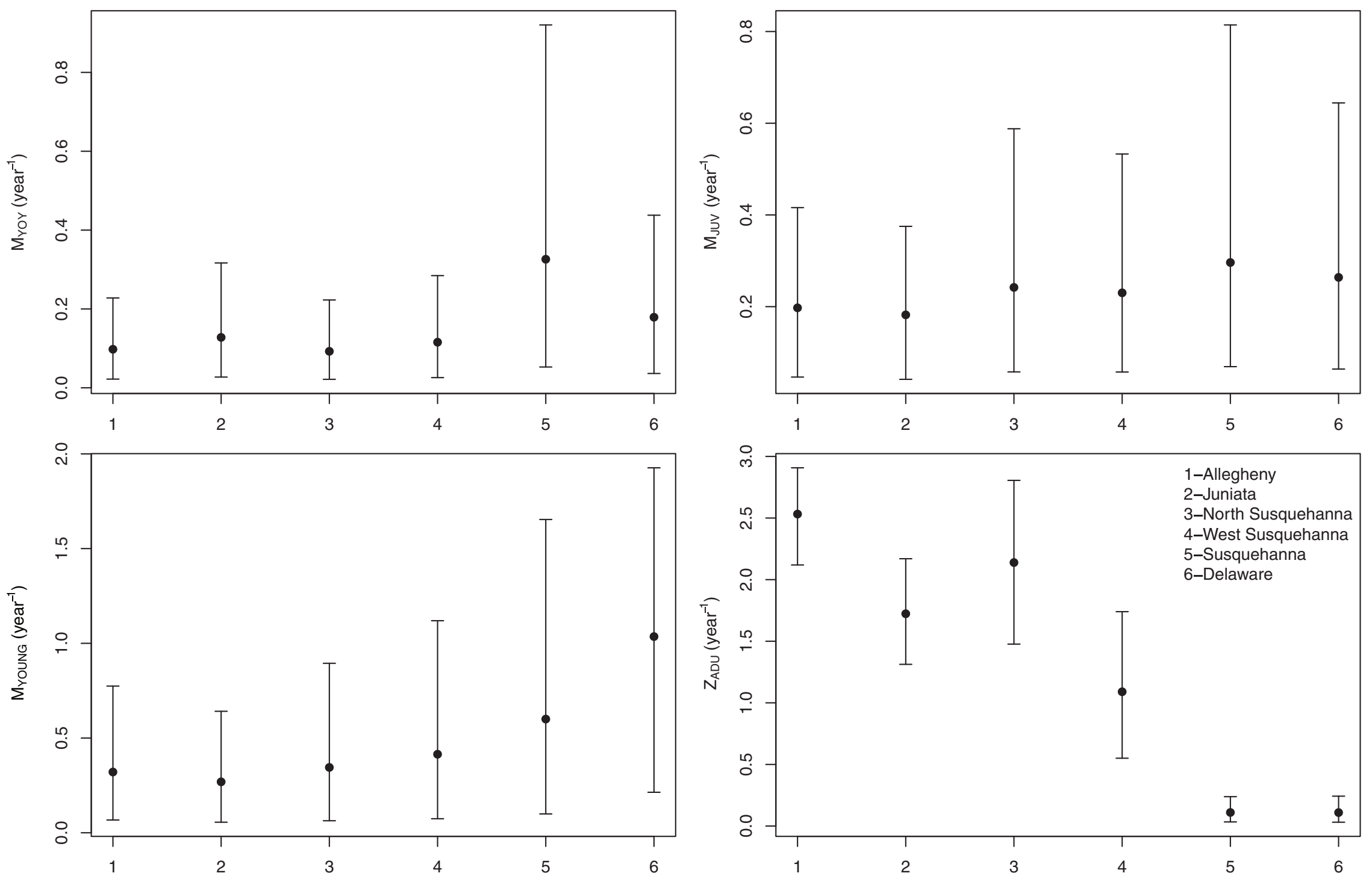

River 
Fig. 7. Estimated mortality parameters (young-of-year: $M_{\mathrm{YOY}}$; juveniles: $M_{\mathrm{JUV}}$; young adults: $M_{\mathrm{YOUNG}}$ : and adults: $Z_{\mathrm{ADU}}$ ) (year-1) from the length-based analysis assuming mortality parameters vary both spatially and temporally. Black solid lines represent posterior means, and grey shaded areas represent $95 \%$ credible intervals.
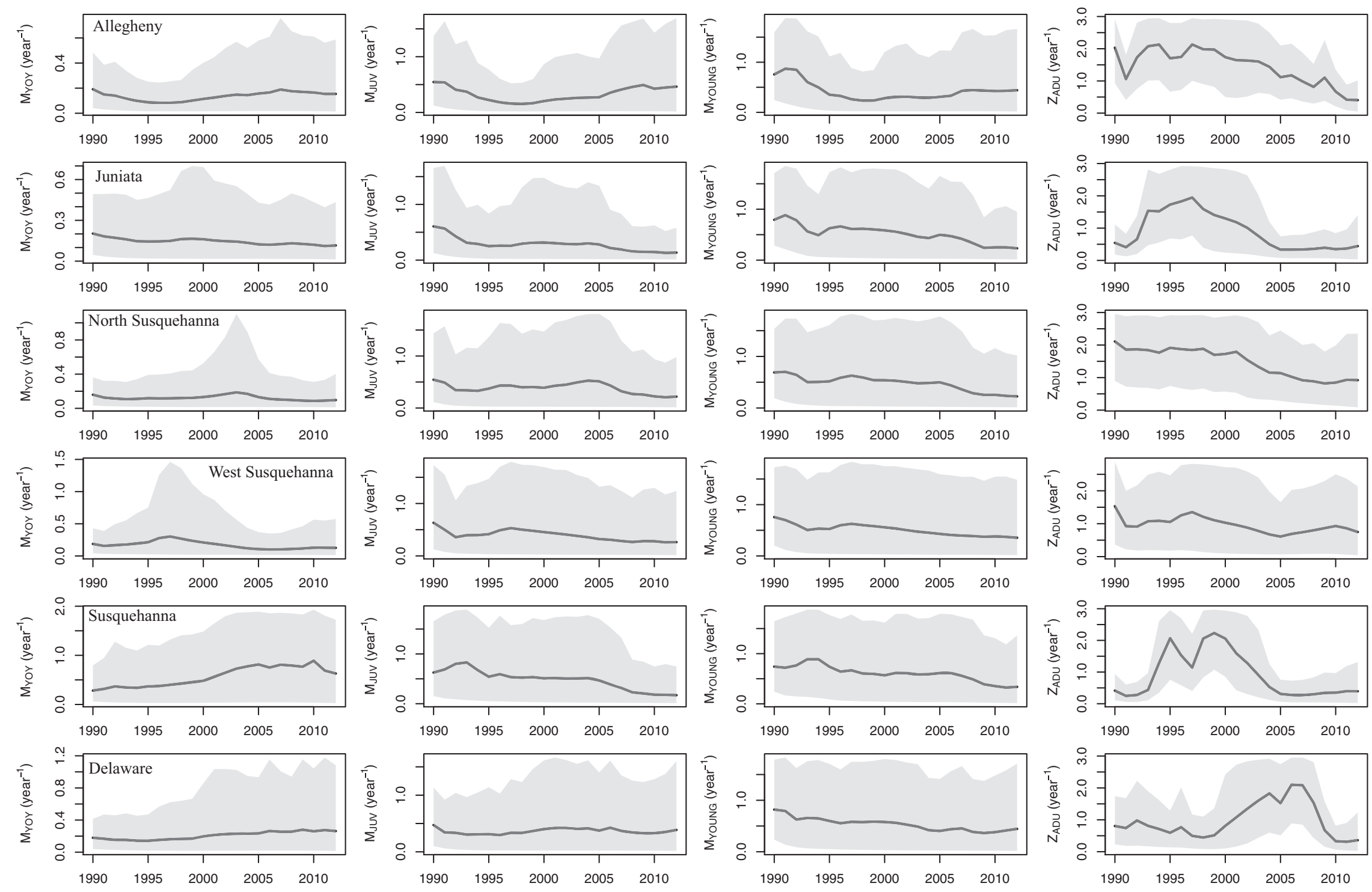

Year 
Fig. 8. Fitted catch-per-unit-effort (CPUE, number of fish per hour) and fitted young-of-year (YOY) catch rate (number of fish per $50 \mathrm{~m}$ shoreline distance) from the length-based analysis assuming mortality parameters vary both spatially and temporally. Black solid lines represent posterior means, grey shaded areas represent 95\% credible intervals, and red rectangles represent observed CPUE and YOY data. [Colour online.]
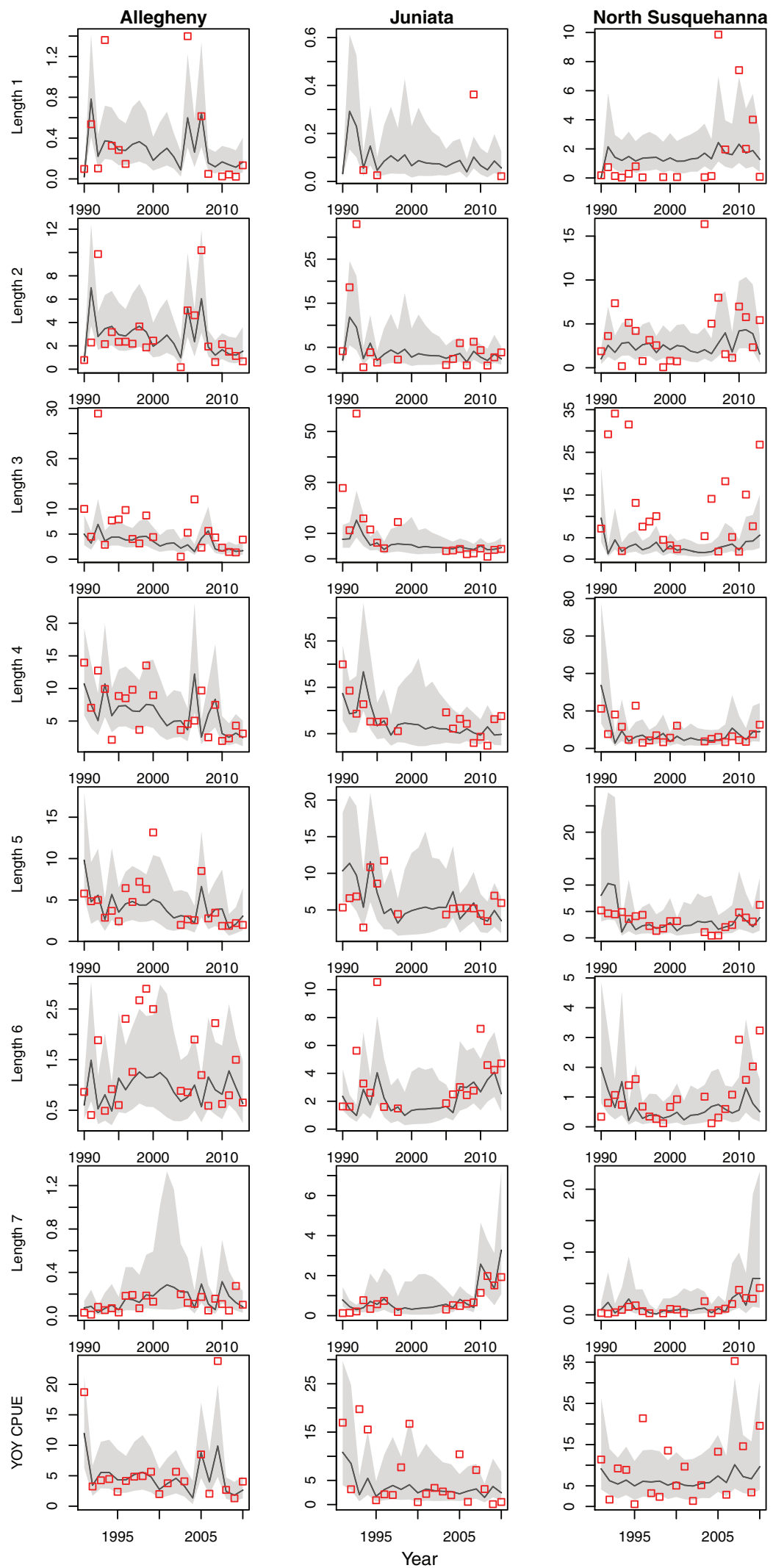
Fig. 8 (concluded).
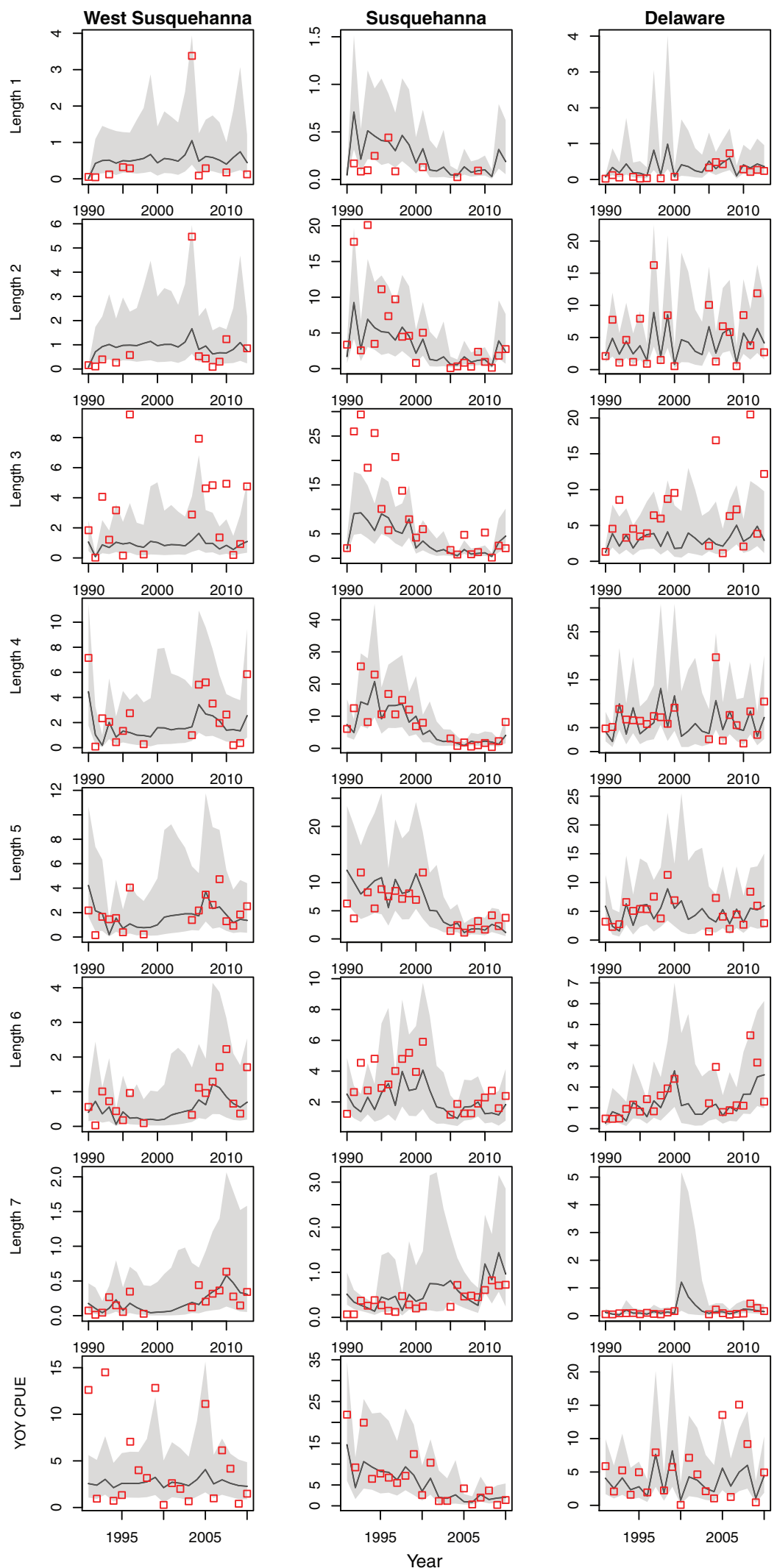
Table 4. Percentage of regressions (among the total of 9000 regressions) that have a significant slope estimate ( $p$ value $<0.05$; \% significant slope), the mean of slope estimates (in parentheses), and percentage of regressions that have a positive slope estimate among those significant-slope regressions (\% positive slope).

\begin{tabular}{|c|c|c|c|c|}
\hline \multirow[b]{2}{*}{ Parameter } & \multicolumn{2}{|c|}{ Spring water temperature $\left({ }^{\circ} \mathrm{C}\right)$} & \multicolumn{2}{|c|}{ Spring flow (cubic feet $\left.\cdot \mathrm{s}^{-1}\right)^{a}$} \\
\hline & \% significant slope & $\%$ positive slope & \% significant slope & \% positive slope \\
\hline$L_{\infty}(\mathrm{mm})$ & $38 \%(-0.061)$ & $0 \%$ & $31 \%\left(-7.46 \times 10^{-6}\right)$ & $0 \%$ \\
\hline$K\left(\right.$ year $\left.^{-1}\right)$ & $48 \%(0.084)$ & $100 \%$ & $67 \%\left(1.12 \times 10^{-5}\right)$ & $100 \%$ \\
\hline$M_{\text {YOY }}\left(\right.$ year $\left.^{-1}\right)$ & $49 \%(0.139)$ & $96 \%$ & $84 \%\left(2.67 \times 10^{-5}\right)$ & $97 \%$ \\
\hline$M_{\text {IVV }}\left(\right.$ year $\left.^{-1}\right)$ & $23 \%(0.053)$ & $69 \%$ & $55 \%\left(1.25 \times 10^{-5}\right)$ & $80 \%$ \\
\hline$M_{\text {YOUNG }}\left(\right.$ year $\left.^{-1}\right)$ & $33 \%(0.122)$ & $91 \%$ & $45 \%\left(8.68 \times 10^{-6}\right)$ & $73 \%$ \\
\hline$Z_{\mathrm{ADU}}\left(\right.$ year $\left.^{-1}\right)$ & $1 \%(-0.091)$ & $2 \%$ & $9 \%\left(-1.07 \times 10^{-5}\right)$ & $6 \%$ \\
\hline
\end{tabular}

${ }^{a} 1$ cubic foot $=28.316 \mathrm{~L}$.

fish at the first two length groups and the YOY catch rate were estimated with relatively great uncertainty for all six rivers.

\section{Relationship of growth and mortality estimates with environmental factors}

Spring water temperature and spring flow were likely positively correlated with growth rates of smallmouth bass, with $48 \%$ and $67 \%$ of regressions showing significant relationship, respectively (Table 4). High young mortality (i.e., mortality of YOY, juveniles, and young adults) was likely to associate with high spring flow, with $84 \%, 55 \%$, and $45 \%$ of regressions showing significant positive relationship for YOY, juveniles, and young adults, respectively. Forty nine percent of regressions showed a significant positive relationship between spring water temperature and YOY mortality.

\section{Discussion}

We established a comprehensive population assessment approach for recreational fisheries that lack catch data and demonstrated this approach with an ecologically and economically important fish species in Pennsylvania, the smallmouth bass, whose population assessment has been compromised due to this lack of catch information. This approach incorporates any available information into the catch-at-age and length analysis framework and is flexible in constructing submodels according to available data (Deriso et al. 1985; Sullivan et al. 1990; Maunder 2003; Maunder and Punt 2013). For example, instead of setting the recruitment to be unknown parameters to estimate as we did in this study, the recruitment could be described by a spawner-recruitment model (e.g., Ricker model; Ricker 1954) if the recruitment of the species is less variable and can be better explained by such a fixed relationship. A submodel to describe catch-and-release dynamics (e.g., Suski et al. 2003) can also be added to the framework if corresponding information is available. Other than applying to species that lack of catch data, our approach could be useful in developing population assessments with erroneous (inaccurate) catch data. For example, for a freshwater recreational fishery that implements catch-and-release, even if catch data are collected, such data become less accurate without being corrected by any information on the mortality associated with catch-release because these data might not accurately reflect the amount of fish removed from the population. This approach could also be used as a model sensitivity scenario to verify traditional population assessment models even when catch data are available.

In this study, we estimated growth and mortality for six populations simultaneously instead of conducting separate analysis for each population by using a hierarchical Bayesian approach. This approach has been used in ecological applications to make efficient use of limited data (e.g., Helser and Lai 2004; Jiao et al. 2011; Midway et al. 2015). It takes into account the individual system variability and similarity simultaneously and thus can provide not only parameters for individual populations (i.e., quantify spatial variability in parameters), but also regional estimation of parameters (i.e., the population-average parameters) that represents multiple populations across rivers. Another benefit of analyzing multiple populations simultaneously is that populations with limited information can borrow data strength from populations with relatively abundant data. For example, the Delaware River population lacked growth data for bass older than 10 years; by estimating parameters together with other populations, it can borrow information from those populations with a better representation of old bass in their growth data, such as Susquehanna River population.

The estimated growth and mortality of smallmouth bass showed great spatial and temporal variability - variability that could be driven by different environmental or biological factors. For example, the average annual flow (1990-2012) in the Susquehanna River was at least 2.5 times that in other rivers and its average spring water temperature was 5\%-30\% higher than other rivers, which may contribute to its higher YOY mortality estimate. For instance, young bass have been found to be sensitive to high flows that may scour them from nests, leading to direct or indirect mortality, and high water temperature during spawning season may increase susceptibility of young fish to disease (Lorantas et al. 2013). Disease outbreak (Lorantas et al. 2013; Smith et al. 2015) and the presence of certain contaminants, such as endocrine disrupting compounds (Reif et al. 2012; Blazer et al. 2014; Shull and Pulket 2015), may also contribute to the elevated YOY mortality in Susquehanna River since 2005. The variability in adult total mortality may be driven by a number of factors, including different fishery management plans across rivers that affect fishing mortality and environmental conditions that influence overall fish health and survival. The legal harvest size for smallmouth bass in Pennsylvania has changed through time, from $254 \mathrm{~mm}$ with yearround harvest in 1986 to $305 \mathrm{~mm}$ (on most rivers) with a closed season (mid-April to mid-June) in 1992. In 2000, the closed season was replaced with a catch-and-release season, which may contribute to declining fishing mortality and to the declining adult total mortality estimates since 2000 for most rivers. Starting in 2011, no harvest of smallmouth bass was allowed in the Susquehanna River and the Juniata River, with only catch-release during nonspawning seasons. The low adult total mortality estimates that are coincident with the no fishing mortality in recent years for these two rivers may be a result from this regulation. In addition, compromised recruitment and survival that has led to lower densities since $\mathbf{2 0 0 0}$ may also contribute to high survival of adults due to less intraspecific competition. Regardless, the spatially varying growth and mortality estimates suggested the benefit from riverspecific management plans for smallmouth bass populations in Pennsylvania because the populations in different rivers may respond differently to management actions and environmental stochasticity (e.g., contamination and land-use change).

Our analysis highlighted the importance of temperature and flow in potentially modifying growth and mortality of smallmouth bass. However, the potential role of chemical contaminants to influence smallmouth bass population dynamics should not be neglected. For example, endocrine disrupting compounds 
that cause developmental abnormalities and reproductive failure have been identified as one potential contributor to smallmouth population decline in the Susquehanna River since 2005 (Blazer et al. 2014; Shull and Pulket 2015), but these were not included in this analysis due to lack of long-term data. Other environmental factors such as prevailing wind exposure and shoreline reticulation have also been shown to influence YOY survival (Lukas and Orth 1995; Rejwan et al. 1999), but were not included in this analysis due to data limitation. In addition, the individual- and population-level effects of contaminants are difficult to elucidate because contaminants usually exist in the environment in the form of a complex mixture, and they interact with abiotic and biotic processes. For example, high concentration of endocrine disrupting compounds were found in surface waters after storms that mobilized them from land to streams (Stoeckel et al. 2012). Nevertheless, such analyses that relate model estimates to potential driving factors do not necessarily imply a direct causal link, but rather provide guidelines for developing hypotheses - ones that might warrant additional research (Shipley 2000; Brooks and Deroba 2015). Field and laboratory experiments that are designed to elucidate the mechanisms of how these factors interact with the species are likely necessary to further test these hypotheses and to help identify the causal factors.

In addition, the important factors that influence growth and mortality may depend on life stage. For example, spring flow was more likely to affect young mortality than adult mortality, which agrees with previous studies (Shuter et al. 1980; Goff 1985; Lukas and Orth 1995; Rejwan et al. 1999; Lorantas et al. 2013). This finding suggested the potential need for life-stage-selective or sizeselective management plans, which is in accordance with existing bass fisheries management in Pennsylvania (Lorantas et al. 2013). In the Pennsylvania bass fisheries, a harvestable size is mandated to allow fish to mature and spawn before harvest and thus to reduce the risk of over-exploitation (Frisk et al. 2002; Tsehaye et al. 2016). The YOY is closely monitored by PFBC through a fisheryindependent survey (e.g., the YOY survey that we used for smallmouth bass in this study), which provides information for evaluating recruitment and population dynamics.

Determination of length groups is critical in length-based analysis. A length interval that is too coarse ignores the individual variability within the length group, while a length interval that is too fine requires more size-specific data. We investigated the sensitivity of our inferences to the length groups we selected by pooling the first three YOY length groups into a single length bin. With this single YOY length bin, the mortality estimates for juveniles and adults remained nearly the same, but the YOY mortality became less estimable. Thus, a fine enough length interval appears to be needed for fast-growing life stages to detect its population dynamics.

High uncertainty in our parameter estimation was always associated with data quantity. For example, in the growth analysis, the estimated length for younger bass had lower uncertainty with more sufficient data compared with the estimates for bass older than 10 years of age. In the length-based analysis, CPUE data were missing during 2001-2004 for most rivers, which resulted in the high uncertainty with the CPUE estimates during this time period. These results emphasized the importance of data quantity and quality in population assessment. With more information, not only can the estimation uncertainty be reduced, but also the population dynamics can be further unfolded. For example, growth parameter $L_{\infty}$ may be better estimated with more old fish observed. With the model framework that we developed, fishing mortality and fishery status (e.g., over-fishing or over-fished) can be estimated by including catch records; determination of length groups can be more biologically meaningful if the CPUE data were recorded by length instead of a $25 \mathrm{~mm}$ length group; parameter estimates can be more robust by using multiple CPUE data sets from different surveys (He 2010); estimation of the regional pa- rameters (i.e., the river-average parameters) can be improved if the data from different rivers were more informative to provide sufficient contrast to better describe the variability in population dynamics across rivers.

It has been long recognized that the natural mortality is relatively high for the young and declines as fish get older (Vetter 1988). However, our natural mortality estimates for young adults were higher than those for the YOY and juveniles. This may be due to several factors. First, since young adults are reaching the harvestable size, it is likely that young adults are caught accidentally followed by a release. Any mortality directly caused by catchrelease and the mortality related to sublethal effect of catchrelease (Bartholomew and Bohnsack 2005; Siepker et al. 2007) were counted towards the natural mortality of young adults in the model, which may have increased its estimates. Second, large predators targeting young adults could also introduce mortality to this length group. For example, flathead catfish (Pylodictis olivaris) are a newly introduced and now popular recreational species in Pennsylvania and known predators upon centrarchids in other parts of the US. Double-crested cormorant (Phalacrocorax auritus) prefer to feed on large-sized smallmouth bass up to $400 \mathrm{~mm}$ and was found closely related to the population decline of young smallmouth bass (ages 3 to 5) in East Lake Ontario (Lantry et al. 1999); they are frequently seen around fresh waters across North America. Lastly, natural mortality is positively correlated to catchability coefficient, and without catch data and with only one abundance index, the estimation of catchability is highly uncertain. Therefore, unlike the population assessments for data-rich species, due to lack of catch data, our analysis with smallmouth bass was limited to focusing on the relative change in parameters over space or time (e.g., spatial and temporal variability in growth and mortality) instead of focusing on the absolute magnitude of the parameters. That said, studies of smallmouth bass in Lake Opeongo, Ontario, Canada, also estimated higher mortality for young adults $(30 \%-48 \%)$ compared with YOY and juveniles $(26 \%)$ (Shuter et al. 1987; Rose 2005; Zipkin et al. 2008).

In conclusion, we established a comprehensive population assessment approach for recreational fisheries that lack catch information and demonstrated the use of such an approach to estimate the spatial and temporal variability in growth and mortality. The growth and mortality of smallmouth bass varied substantially across space and over time for smallmouth bass in Pennsylvania rivers. Spring water temperature and spring flow may play an important role affecting growth and young bass mortality. The factors influencing growth and mortality may depend on life stage. The populations with great spatial and temporal variability in key life-history characteristics may benefit from site-specific management plans and may respond to land-use change and climate change differently.

\section{Acknowledgements}

We thank Valery Forbes, Dana Kolpin, Vicki Blazer, Patrick Phillips, Donald Tillitt, and Kelly Smalling for discussions that helped improve this manuscript. This research was supported by the US Geological Survey Contaminants Biology Program. Any use of trade, firm, or product names is for descriptive purposes only and does not imply endorsement by the US Government.

\section{References}

Allen, M.S., Walters, C.J., and Myers, R. 2008. Temporal trends in largemouth bass mortality, with fishery implications. N. Am. J. Fish. Manage. 28(2): 418427. doi:10.1577/M06-264.1.

Arway, J.A., and Smith, G. 2013. The Susquehanna River - a fishery in decline. Fisheries, 38(5): 235-236. doi:10.1080/03632415.2013.785395.

Bartholomew, A., and Bohnsack, J.A. 2005. A review of catch-and-release angling mortality with implications for no-take reserves. Rev. Fish Biol. Fish. 15(1-2): 129-154. doi:10.1007/s11160-005-2175-1.

Beamesderfer, R.C., and North, J.A. 1995. Growth, natural mortality, and predicted response to fishing for largemouth bass and smallmouth bass popu- 
lations in North America. N. Am. J. Fish. Manage. 15(3): 688-704. doi:10.1577| 1548-8675(1995)015<0688:GNMAPR>2.3.CO;2.

Blazer, V., Iwanowicz, D., Walsh, H., Sperry, A., Iwanowicz, L., Alvarez, D., Brightbill, R., Smith, G., Foreman, W., and Manning, R. 2014. Reproductive health indicators of fishes from Pennsylvania watersheds: association with chemicals of emerging concern. Environ. Monit. Assess. 186(10): 6471-6491. doi:10.1007/s10661-014-3868-5. PMID:24934131.

Brooks, E.N., and Deroba, J.J. 2015. When "data” are not data: the pitfalls of post hoc analyses that use stock assessment model output. Can. J. Fish. Aquat. Sci. 72(4): 634-641. doi:10.1139/cjfas-2014-0231.

Chen, Y., Hunter, M., Vadas, R., and Beal, B. 2003. Developing a growth-transition matrix for the stock assessment of the green sea urchin (Strongylocentrotus droebachiensis) off Maine. Fish. Bull. 101(4): 737-744.

Deriso, R.B., Quinn, T.J., II, and Neal, P.R. 1985. Catch-age analysis with auxiliary information. Can. J. Fish. Aquat. Sci. 42(4): 815-824. doi:10.1139/f85-104.

Dudgeon, D., Arthington, A.H., Gessner, M.O., Kawabata, Z.-I., Knowler, D.J., Lévêque, C., Naiman, R.J., Prieur-Richard, A.-H., Soto, D., Stiassny, M.L., and Sullivan, C.A. 2006. Freshwater biodiversity: importance, threats, status and conservation challenges. Biol. Rev. 81(2): 163-182. doi:10.1017/S1464793105006950. PMID:16336747.

Eveson, J.P., Polacheck, T., and Laslett, G.M. 2007. Consequences of assuming an incorrect error structure in von Bertalanffy growth models: a simulation study. Can. J. Fish. Aquat. Sci. 64(4): 602-617. doi:10.1139/f07-036.

Frisk, M., Miller, T., and Fogarty, M. 2002. The population dynamics of little skate Leucoraja erinacea, winter skate Leucoraja ocellata, and barndoor skate Dipturus laevis: predicting exploitation limits using matrix analyses. ICES J. Mar. Sci. 59(3): 576. doi:10.1006/jmsc.2002.1177.

Gelman, A., and Hill, J. 2007. Data analysis using regression and multilevel/ hierarchical models. Cambridge, New York

Goff, G.P. 1985. Environmental influences on annual variation in nest success of smallmouth bass, Micropterus dolomieui, in Long Point Bay, Lake Erie. Environ. Biol. Fishes, 14(4): 303-307. doi:10.1007/BF00002635.

Gulland, J. 1983. Fish stock assessment. Wiley, Chichester, UK.

$\mathrm{He}, \mathrm{Q}$. 2010. Investigating the performance of process-observation-errorestimator and robust estimators in surplus production model: a simulation study. M.S., Fisheries and Wildlife Sciences, Virginia Tech University.

Helser, T.E., and Lai, H.L. 2004. A Bayesian hierarchical meta-analysis of fish growth: with an example for North American largemouth bass, Micropterus salmoides. Ecol. Model. 178(3): 399-416. doi:10.1016/j.ecolmodel.2004.02.013.

Hilborn, R., Pikitch, E.K., and McAllister, M.K. 1994. A Bayesian estimation and decision analysis for an age-structured model using biomass survey data. Fish. Res. 19(1-2): 17-30. doi:10.1016/0165-7836(94)90012-4.

Hoff, P.D. 2009. A first course in Bayesian statistical methods. Springer, New York.

Hoopes, R. 1987. Smallmouth bass age and size at maturity. Fisheries Management Report. Pennsylvania Fish and Boat Commission.

Jiao, Y., Cortes, E., Andrews, K., and Guo, F. 2011. Poor-data and data-poor species stock assessment using a Bayesian hierarchical approach. Ecol. Appl. 21(7): 2691-2708. doi:10.1890/10-0526.1. PMID:22073653.

Jiao, Y., Smith, E.P., O'Reilly, R., and Orth, D.J. 2012. Modelling non-stationary natural mortality in catch-at-age models. ICES J. Mar. Sci. 69(1): 105-118. doi: 10.1093/icesjms/fsr184.

Kimura, D.K. 2008. Extending the von Bertalanffy growth model using explanatory variables. Can. J. Fish. Aquat. Sci. 65(9): 1879-1891. doi:10.1139/F08-091.

Lantry, B., Eckert, T., and Schneider, C. 1999. The relationship between the abundance of smallmouth bass and double-crested cormorants in the eastern basin of Lake Ontario. New York State Department of Environmental Conservation, Cape Vincent, New York.

Lorantas, R., Kristine, D., and Hobbs, C. 2013. Largemouth bass, smallmouth bass, and spotted bass management and fishing in Pennsylvania. Pennsylvania Fish and Boat Commission.

Lukas, J.A., and Orth, D.J. 1995. Factors affecting nesting success of smallmouth bass in a regulated Virginia stream. Trans. Am. Fish. Soc. 124(5): 726-735. doi:10.1577/1548-8659(1995)124<0726:FANSOS>2.3.CO;2.

MacRae, P.S.D., and Jackson, D.A. 2001. The influence of smallmouth bass (Micropterus dolomieu) predation and habitat complexity on the structure of littoral zone fish assemblages. Can. J. Fish. Aquat. Sci. 58(2): 342-351. doi:10. 1139/f00-247.

Maunder, M.N. 2003. Paradigm shifts in fisheries stock assessment: from integrated analysis to Bayesian analysis and back again. Nat. Resour. Model. 16(4): 465-476. doi:10.1111/j.1939-7445.2003.tb00123.x.
Maunder, M.N., and Punt, A.E. 2013. A review of integrated analysis in fisheries stock assessment. Fish. Res. 142: 61-74. doi:10.1016/j.fishres.2012.07.025.

Midway, S.R., Wagner, T., Arnott, S.A., Biondo, P., Martinez-Andrade, F., and Wadsworth, T.F. 2015. Spatial and temporal variability in growth of southern flounder (Paralichthys lethostigma). Fish. Res. 167: 323-332. doi:10.1016/j.fishres. 2015.03.009.

Myers, R.A., MacKenzie, B.R., Bowen, K.G., and Barrowman, N.J. 2001. What is the carrying capacity for fish in the ocean? A meta-analysis of population dynamics of North Atlantic cod. Can. J. Fish. Aquat. Sci. 58(7): 1464-1476. doi:10.1139/ f01-082.

Quinn, T.J., and Deriso, R.B. 1999. Quantitative fish dynamics. Oxford University Press, New York.

Reif, A.G., Crawford, J.K., Loper, C.A., Proctor, A., Manning, R., and Titler, R. 2012. Occurrence of pharmaceuticals, hormones, and organic wastewater compounds in Pennsylvania waters, 2006-09. US Geological Survey Scientific Investigations Report 5106: 99

Rejwan, C., Collins, N.C., Brunner, L.J., Shuter, B.J., and Ridgway, M.S. 1999. Tree regression analysis on the nesting habitat of smallmouth bass. Ecology, 80(1): 341-348. doi:10.1890/0012-9658(1999)080[0341:TRAOTN]2.0.CO;2.

Ricker, W.E. 1954. Stock and recruitment. J. Fish. Res. Board Can. 11(5): 559-623. doi:10.1139/f54-039.

Rose, K.A. 2005. Lack of relationship between simulated fish population responses and their life history traits: inadequate models, incorrect analysis, or site-specific factors? Can. J. Fish. Aquat. Sci. 62(4): 886-902. doi:10.1139/f05049.

Shipley, B. 2000. Cause and correlation in biology: a user's guide to path analysis, structural equations and causal Inference. Cambridge University Press, New York.

Shull, D., and Pulket, M. 2015. Causal analysis of the smallmouth bass decline in the Susquehanna and Juniata rivers. Pennsylvania Department of Environmental Protection.

Shuter, B., MacLean, J., Fry, F., and Regier, H. 1980. Stochastic simulation of temperature effects on first-year survival of smallmouth bass. Trans. Am. Fish. Soc. 109(1): 1-34. doi:10.1577/1548-8659(1980)109<1:SSOTEO>2.0.CO;2.

Shuter, B.J., Matuszek, J.E., and Regier, H.A. 1987. Optimal use of creel survey data in assessing population behaviour: Lake Opeongo lake trout (Salvelinus namaycush) and smallmouth bass (Micropterus dolomieui), 1936-83. Can. J. Fish. Aquat. Sci. 44(S2): s229-s238. doi:10.1139/f87-325.

Siepker, M., Ostrand, K., Cooke, S., Philipp, D., and Wahl, D. 2007. A review of the effects of catch-and-release angling on black bass, Micropterus spp.: implications for conservation and management of populations. Fish. Manage. Ecol. 14(2): 91-101. doi:10.1111/j.1365-2400.2007.00529.x.

Smith, G.D., Blazer, V.S., Walsh, H.L., Iwanowicz, L.R., Starliper, C., and Sperry, A.J. 2015. The effects of disease-related mortality of young-of-year smallmouth bass on the population characteristics in the Susquehanna River basin, Pennsylvania and potential implications to conservation of black bass diversity. Am. Fish. Soc. Symp. 82: 319-332.

Smucker, B., Rosenberger, J., and Shumway, D. 2010. Susquehanna/Juniata river creel survey 2007. The Pennsylvania State University Statistical Consulting Center; Final report prepared for Pennsylvania Fish and Boat Commission.

Stoeckel, J.A., Morris, J., Ames, E., Glover, D.C., Vanni, M.J., Renwick, W., and González, M.J. 2012. Exposure Times to the Spring Atrazine Flush Along a Stream-Reservoir System. JAWRA J. Am. Water Resour. Assoc. 48(3): 616-634. doi:10.1111/j.1752-1688.2011.00633.x.

Sullivan, P.J., Lai, H.-L., and Gallucci, V.F. 1990. A catch-at-length analysis that incorporates a stochastic model of growth. Can. J. Fish. Aquat. Sci. 47(1): 184-198. doi:10.1139/f90-021.

Suski, C., Svec, J., Ludden, J., Phelan, F., and Philipp, D. 2003. The effect of catch-and-release angling on the parental care behavior of male smallmouth bass. Trans. Am. Fish. Soc. 132(2): 210-218. doi:10.1577/1548-8659(2003)132 $<0210$ :TEOCAR>2.0.CO;2.

Tsehaye, I., Roth, B.M., and Sass, G.G. 2016. Exploring optimal walleye exploitation rates for northern Wisconsin ceded territory lakes using a hierarchical Bayesian age-structured model. Can. J. Fish. Aquat. Sci. 73(9): 1413-1433. doi: 10.1139/cjfas-2015-0191.

Vetter, E. 1988. Estimation of natural mortality in fish stocks: a review. Fish. Bull. 86(1): 25-43.

von Bertalanffy, L. 1938. A quantitative theory of organic growth (inquiries on growth laws. II). Hum. Biol. 10(2): 181-213.

Zipkin, E.F., Sullivan, P.J., Cooch, E.G., Kraft, C.E., Shuter, B.J., and Weidel, B.C. 2008. Overcompensatory response of a smallmouth bass (Micropterus dolomieu) population to harvest: release from competition? Can. J. Fish. Aquat. Sci. 65(10): 2279-2292. doi:10.1139/F08-133. 
Copyright of Canadian Journal of Fisheries \& Aquatic Sciences is the property of Canadian Science Publishing and its content may not be copied or emailed to multiple sites or posted to a listserv without the copyright holder's express written permission. However, users may print, download, or email articles for individual use. 